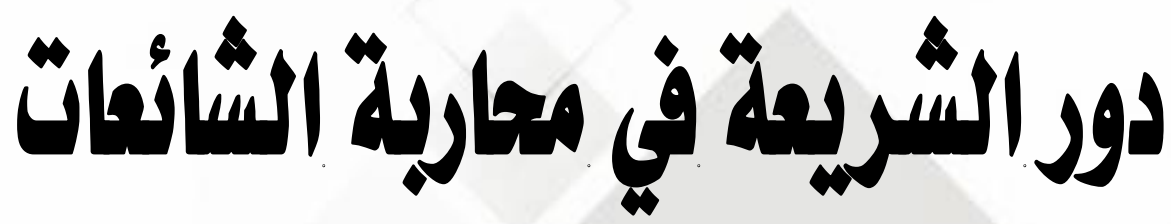

وألّر ذلكاك على الاستقرّار

(الراسة تطبيتية على مل القذلن)

\author{
إعداد \\ د. مدحمد سالم ناجي سالم \\ المعيد بقسم أصول الفقه بالكلية
}





\section{دور الشريعة في محاربة الشائعات وأثر ذلك على الاستقرار (دراسة تطبيقية على حد القذف)}

$$
\text { محمد سالم ناجي سالم }
$$

قسم أصول الفقه، كلية الشريعة والقانون، جامعة الأزهر، القاهرة،

$$
\text { جمهورية مصر العربية. }
$$

البريد الإلكتروني: mohamedsalem.12@azhar.edu.eg

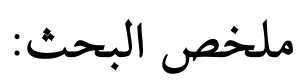

يتناول البحث خطر الشائعات وما يترتب عليها من تهديد لاستقرار المجتمع.

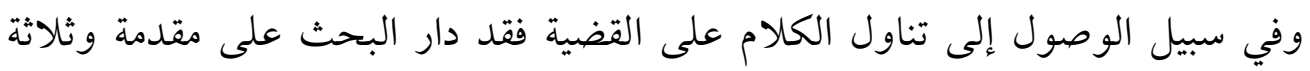

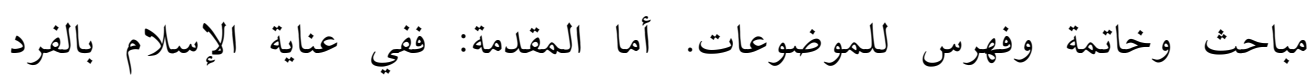

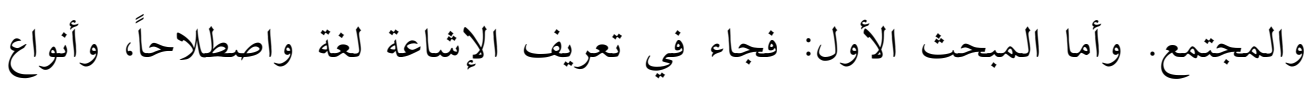

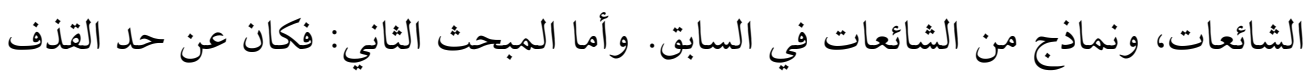

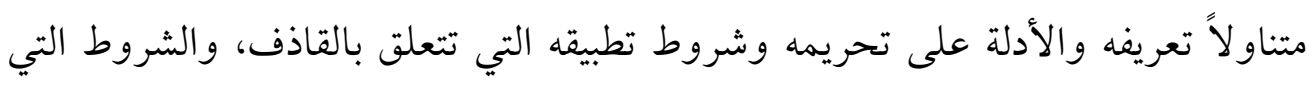

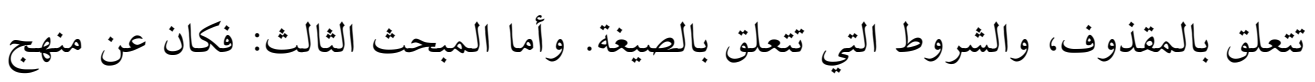

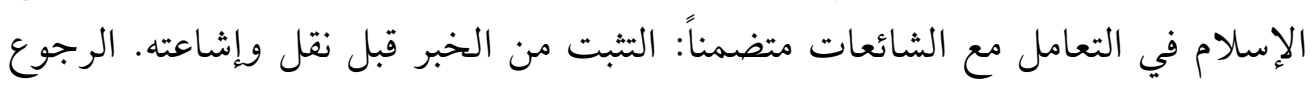

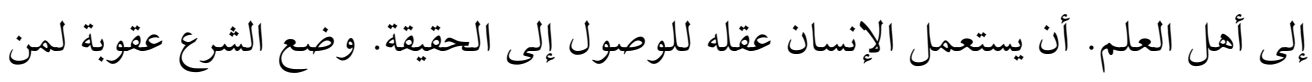
لا يتثبت من صحة الكلام. الكلمات المفتاحية: الإشاعة، حد الثدم القذف، القاذف، المقذوف، استقرار

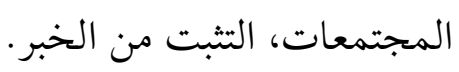


The role of Shariah in fighting rumors and its impact on stability

(Applied study on the limit of ejaculation)

Mohamed Salem Nagy Salem

Department of Jurisprudence, Faculty of Shariah and Law, AlAzhar University, Cairo, Arab Republic of Egypt.

E-mail: mohamedsalem.12@azhar.edu.eg

\section{Abstract :}

The research deals with the danger of rumors and the consequent threat to the stability of society. In order to reach a discussion of the issue, the research presents an introduction, three chapters, a conclusion and an index of topics. As for the introduction: The concern of Islam for the individual and society. As for the first topic: It defines rumors, linguistically and idiomatically, and the types of rumors, and examples of rumors in the past. As for the second topic: It is about the limit of slander, addressing its definition, the evidence for its prohibition, the conditions for its application that relate to the slanderer, the conditions related to the projectile, and the conditions related to the formula. As for the third topic: It is about the approach of Islam in dealing with rumors, including: Verify the news before transmitting and spreading it. Asking for the opinions of the scholars. - A person has to use his mind to reach the truth. Shariah law sets a penalty for those who do not verify the authenticity of the speech.

Keywords: Rumor, The extent of slander, The slanderer, The slandered, The stability of societies, The verification of the news. 


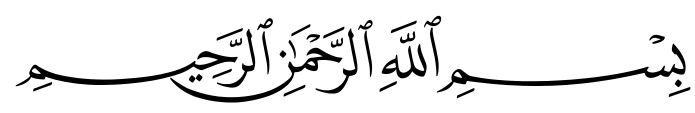

الحمد لله رب العالمين، والصلاة والسلام على المبعوث رحمة

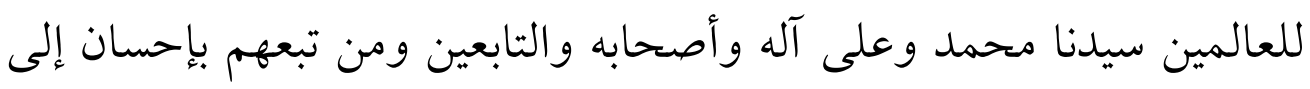

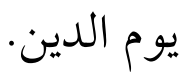
وبعد...

فإن الإسلام حافظ على أتباعه من كل ما ينغص عليهم معيشتهم، فالنبي

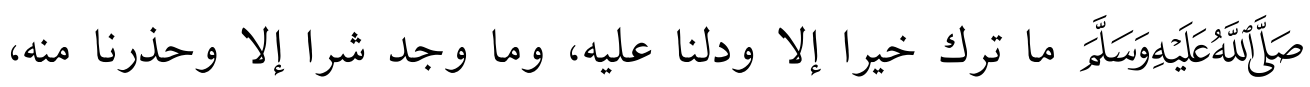

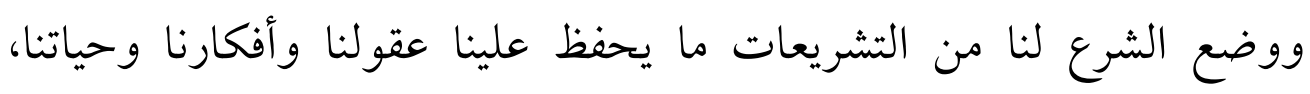

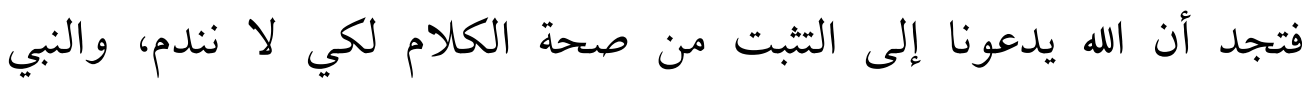

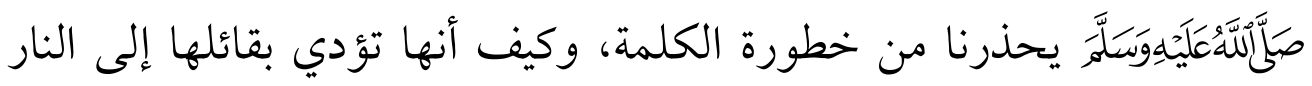

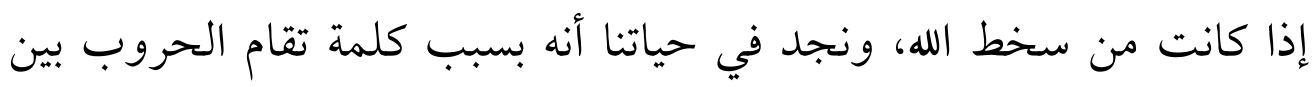

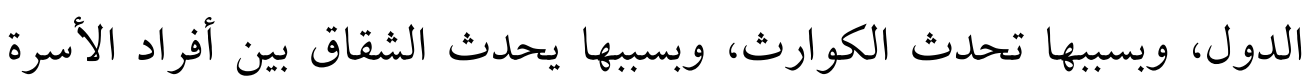

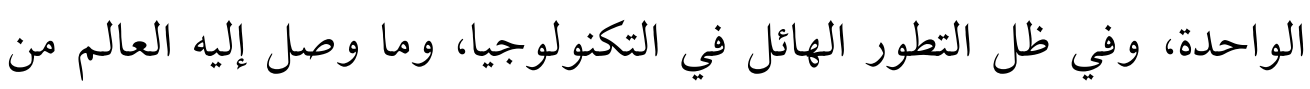

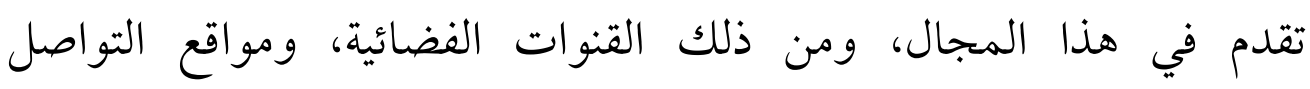

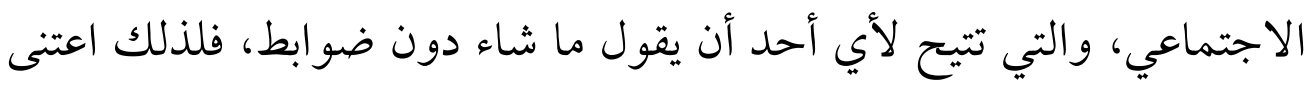

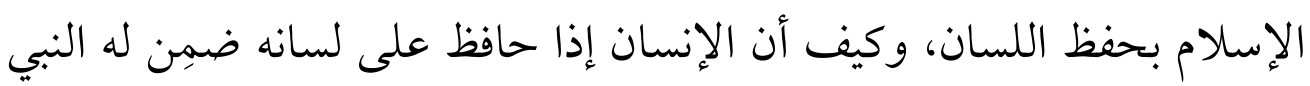

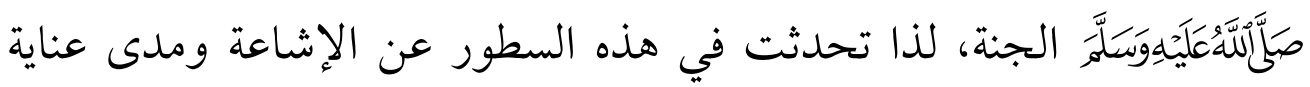

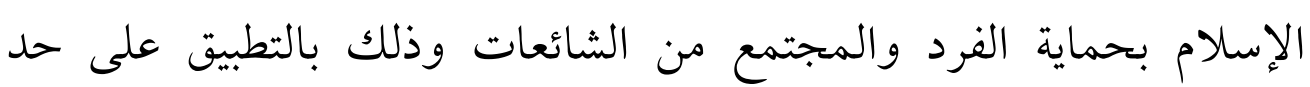




\section{خطة البحث}

اشتمل هذا البحث على مقدمة وثلاثة مباحث وخاتمة وفهرس

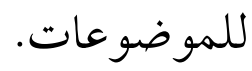

أما المقدمة: فقد تحدثت فيها عن عناية الإسلام بالفرد والمجتمع. وأما المبحث الأول: تحدثت فيه عن تعريف الإشاعة لغة واصطلاحاً، وأنواع الشائعات، ونماذج من الشائعات في السابق. وأما المبحث الثاني: فتحدثت فيه عن حد القذف متناولاً تعريفه والأدلة على تحريمه وشروط تطبيقه التي تتعلق بالقاذف، والشروط التي تتعلق فئل بالمقذوف، والشروط التي تتعلق بالصيغة. وأما المبحث الثالث: فتحدثت فيه عن منهج الإسلام في التعامل مع

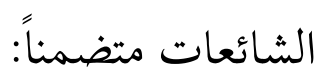
- - التثبت من الخبر قبل نقل وإشاعته.

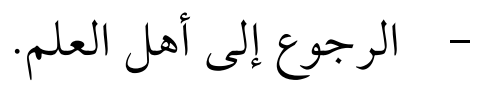
- وضع الشرع عقوبة لمن لا يتثبت من صحة الكلام. وأما الخاتمة: فتحدثت فيها عن أهم النتائج. 


\section{المبحث الأول}

\section{تمريف الإشاعة}

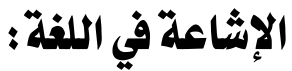

إن كلمة الإشاعة في قواميس اللغة تدور حول الانتشار والتفرق والوصول إلى كل فرد أو عدد كبير من الأفراد يقال: شاعَ الخبرُ يَشيعُ شَيْعوعَةً، أي ذاع ('). وقولهم: هذا خبر شائع، وقد شاع في الناس، معناه: قد اتصل بكل أحد، فاستوى علم الناس به، ولم يكن علمه عند بعضهم دون

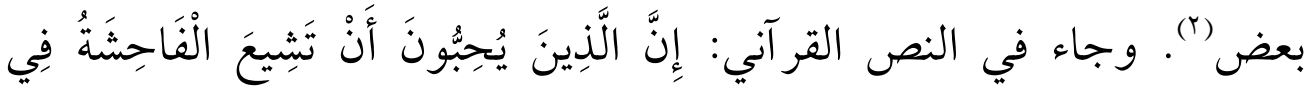

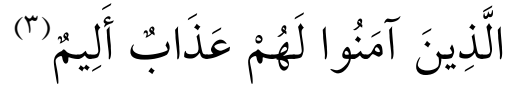

\section{الإشاعة في الاصطلاح:}

عرفت الإشاعة بتعريفات كثيرة أذكر منها:

الإشاعة هي: بث خبر من مصدر ما في ظرف معين، ولهدف يبغيه

المصدر دون علم الآخرين، وانتشار هذا الخبر بين أفراد مجموعة معينة (؛). أو هي: عبارة عن رواية مصطنعة عن شخص أو جماعة أو دولة يتم تداولها شفهياً أو إعلامياً، وهي مطروحة لكي يصدقها الجمهور دون أن

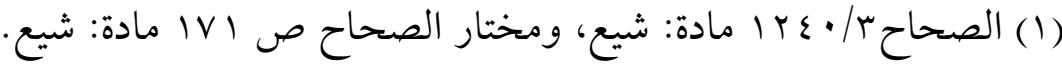

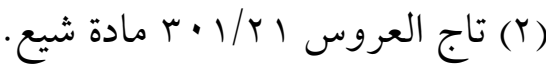

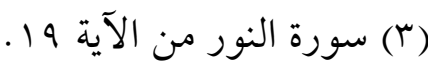

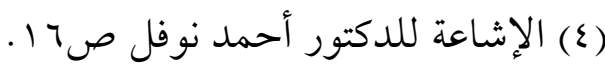


تتضمن مصادرها ودون أن تقدم دلائل مؤكدة على كونها واقعية(1). أنواع الإشاعات

تتعدد أنواع الإشاعات تبعاً للخبر المشاع، والهدف من الإشاعة، وأذكر

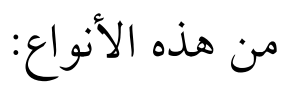

الإشاعة الحقيقية: هي ذات مصدر موثوق وحقيقة مؤكدة تقال لاستبيان تأثير الخبر على سامعه ويتم على ضوئه استنتاج ما يحتاجه ذلك الموضوع من تعديلات وتغييرات قبل إلزام تنفيذه أو تطبيقه. الإشاعة الإستنتاجية: وهي نتيجة استقراء تطبيقات معينة خلال فترة محددة، وتصدر من أي شخص بحسب تعلمه وثثافته وإلمامه بجوانب الموضوع، وتبعا لذلك تصدق هذه الإشاعة في كثير من الأحيان كلما زاد ذلك الشخص قربا من الموضوع إلماما ومعرفة، وتخيب كلما زاد جهله فيه.

الإشاعة الحالمة: وهي نتيجة مشاعر نرجسية وأوهام وتمنيات تصدر عن فئة لا تعيش الواقع بجميع أبعاده ومعطياته وميئوس من صدقها كما يئس الكفار من أصحاب القبور.

الإشاعة الكاذبة: ومصدرها مَن نشأ في بيئة غير صحيحة درج على إلقاء الكلام جزافا، ويكره من يحقق معه في مصداقية كلامه، ولا يحب بلإسبه المواجهة، ونجده ينتقي سامعيه حتى لا يكون عرضة للمسائلة.

(1) أساليب مواجهة الشائعات ص r Tr. 
الإشاعة الحاقدة: وهذه أخطر أنواع الإشاعات على الإطلاق بدءا من

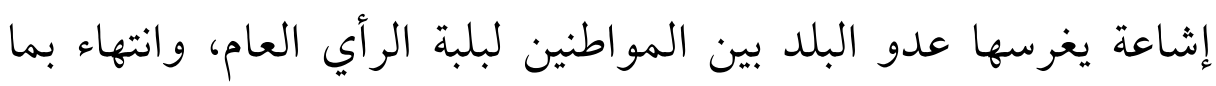

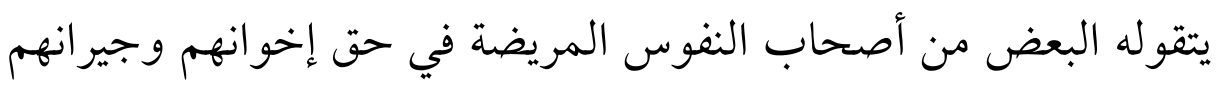

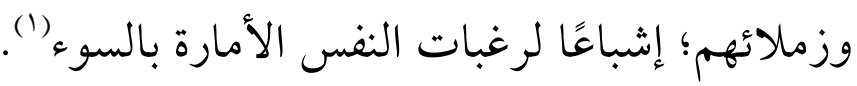
الإشاعة الزاحفة: وهي التي تروج ببطء وهمس وبطريقة سرية(؟).

\section{نماذج من الإشاعات:}

إذا نظرنا إلى الإشاعة نجد أنها قديمة منذ أن خلق الله البشرية وهي

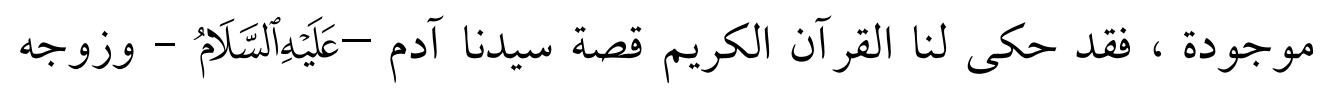

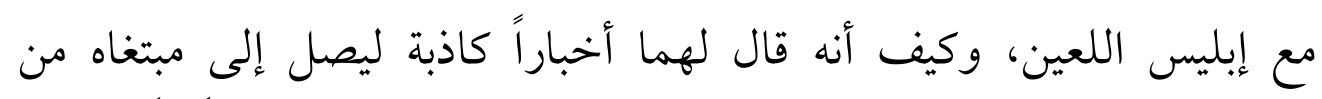

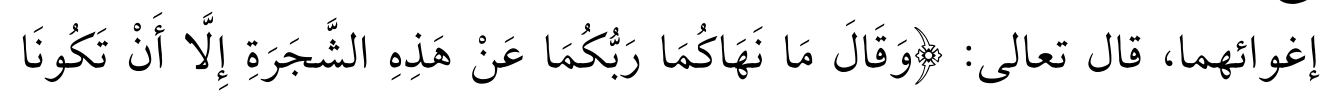

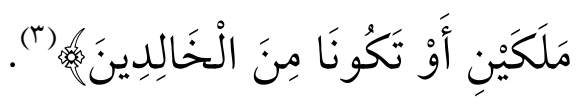

ثم تتو الى بعد ذلك الإشاعات في جانب أفضل البشرية على الإطلاق

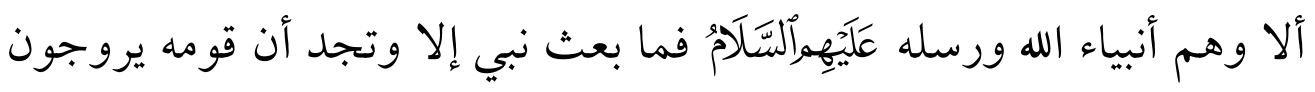

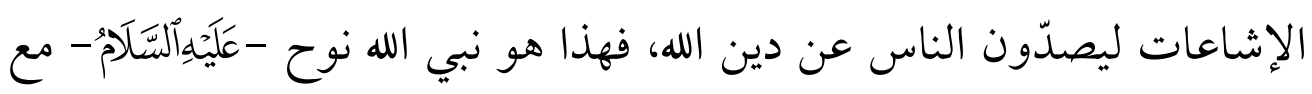

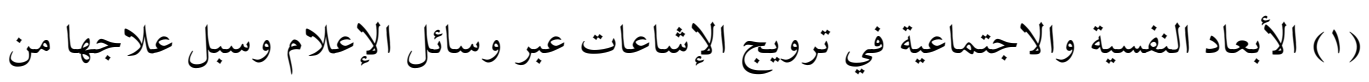

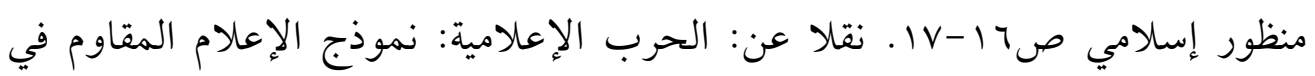
لبنان.

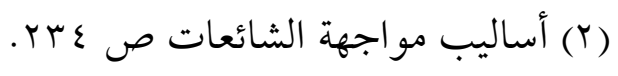

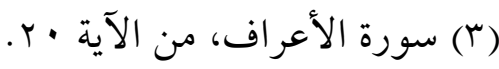




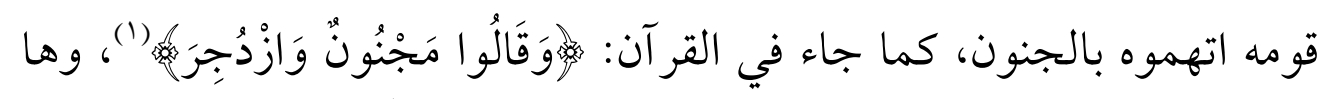

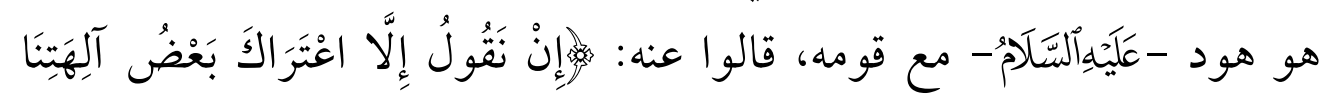

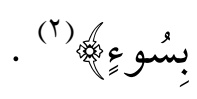

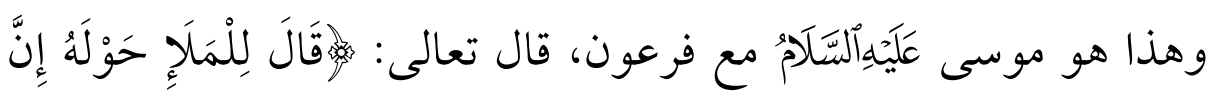

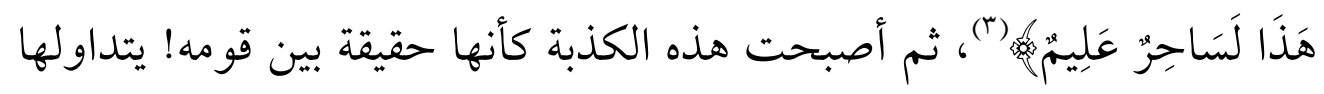

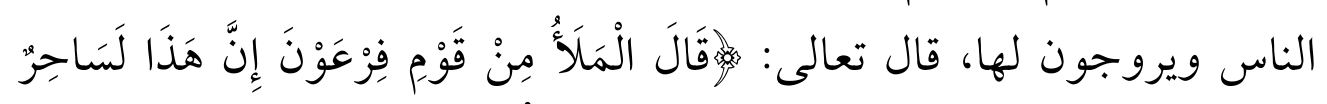

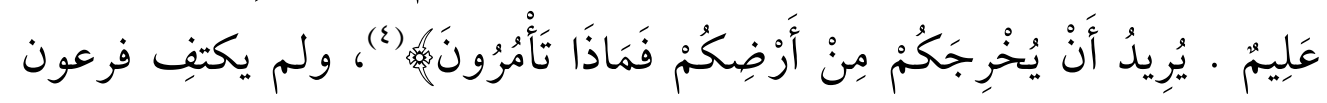
بقول الإشاعة بل روج لها وآرسل جنوده ليشيعوا في الناس أن هذا الرجل لا

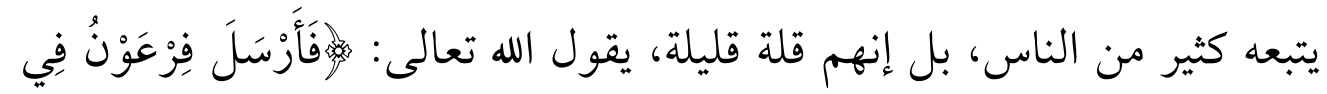

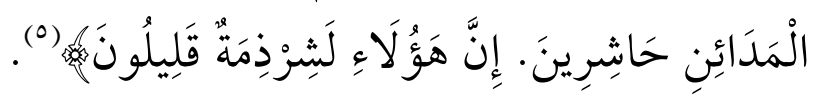

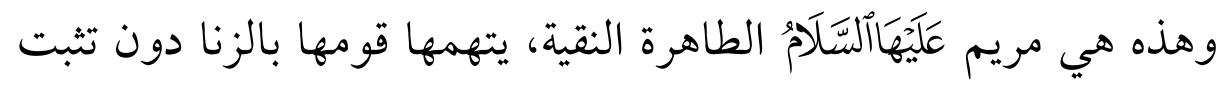

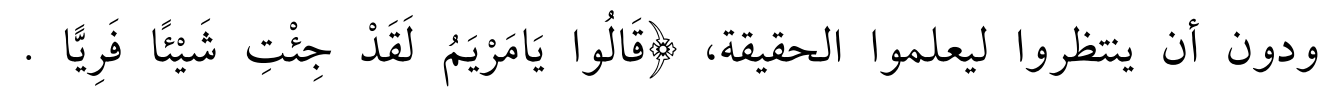

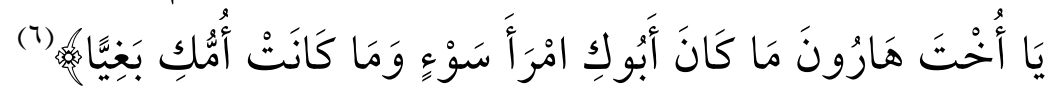

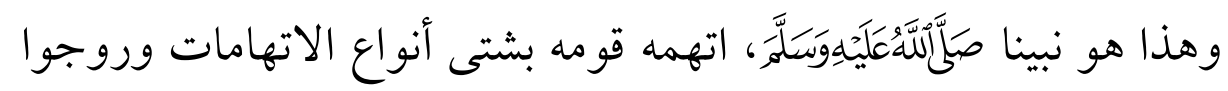
ما استطاعوا لكل أنواع الإشاعات بغية أن يصلوا إلى ما أرادوا، على أنه

$$
\begin{aligned}
& \text { (1) سورة القمر، من الآية } 9 . \\
& \text { (r) سورة هود، من الآية عه. الآية } 4 .
\end{aligned}
$$

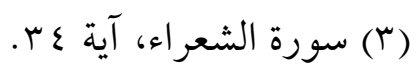

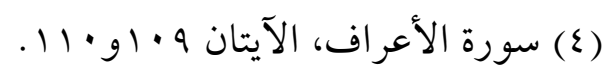

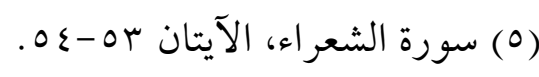

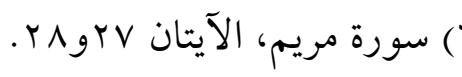




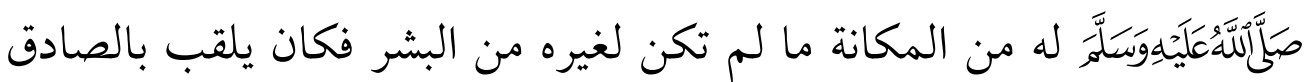

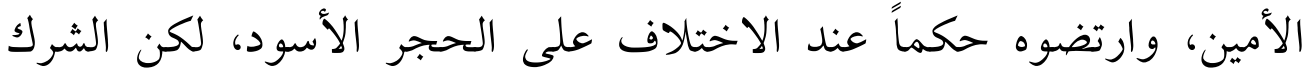

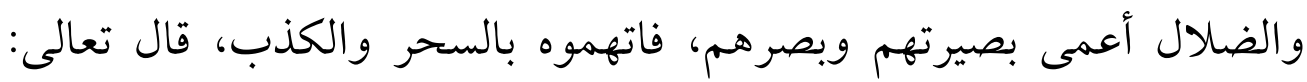

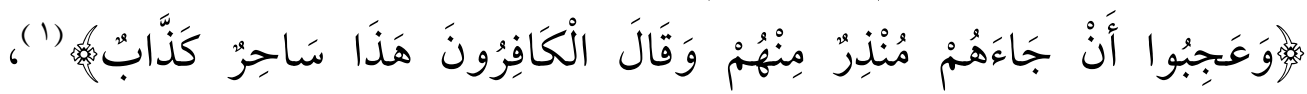

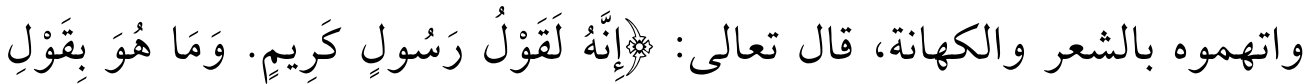

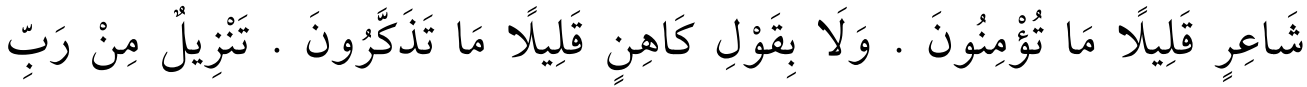

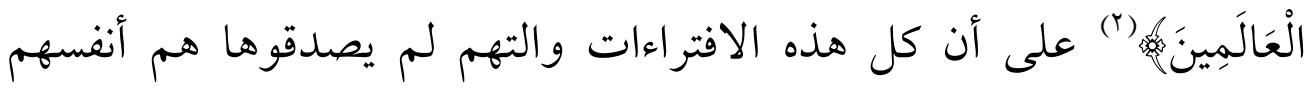

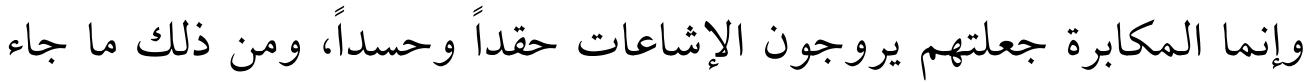

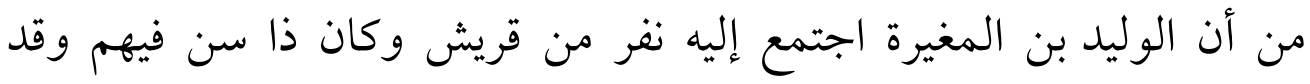

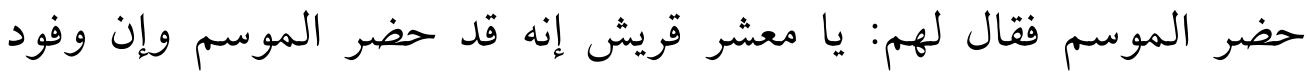

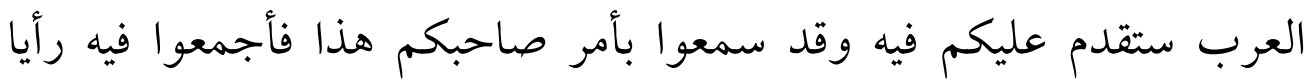

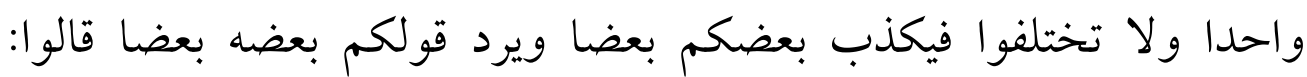

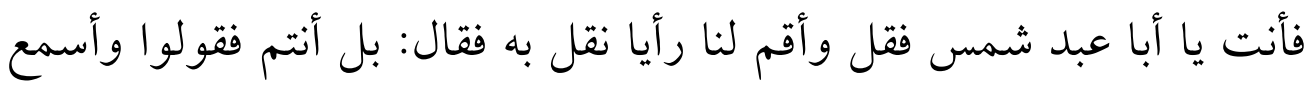

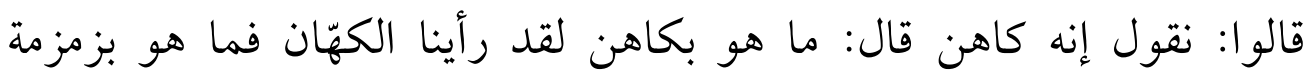

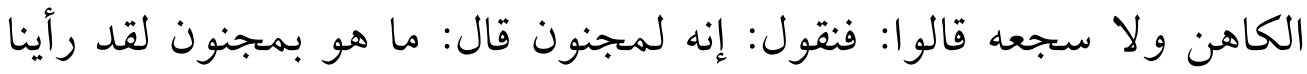
الجنون وعرفناه فما هو بخنقه ولا تخالجه ولا وسوسته قالوا: فنقول إنه شاعر ، قال ما هو بشاعر لقد عرفنا الشعر كله رجزه وهزجه وقريضه ومقبوضه ومبسوطه فما هو بالشاعر قالوا: فنقول ساحر قال: ما هو بساحر

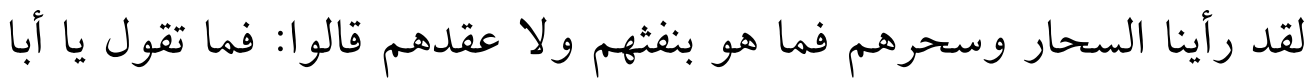

$$
\text { (1) سورة ص ، آية ع. سورة الحاقة، الآيات من ·ع -بrع. }
$$


عبد شمس؟ قال: و الله إن لقوله لحلاوة، وإن أصله لمغدق، وإن فرعه لجناة

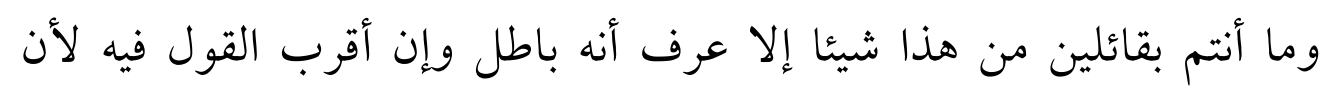

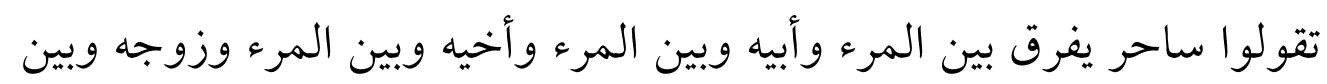

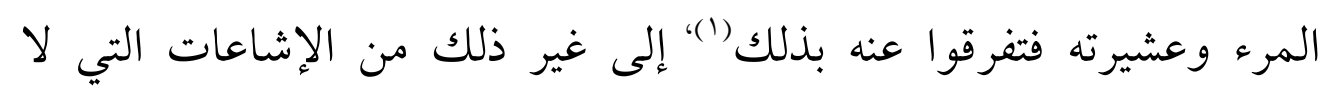
يقصدون من ورائها إلا تضليل الناس عن دين رب عند العالمين.

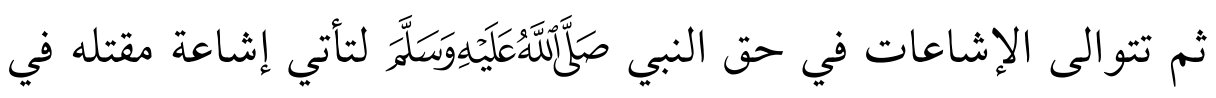

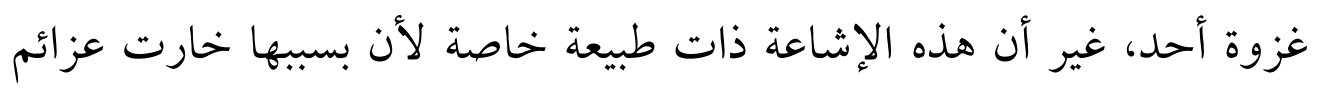

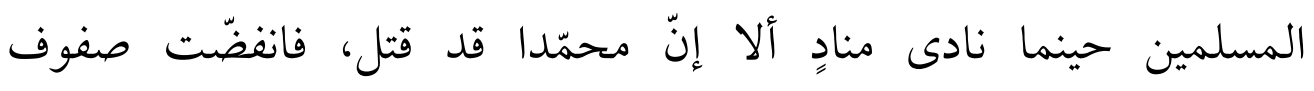

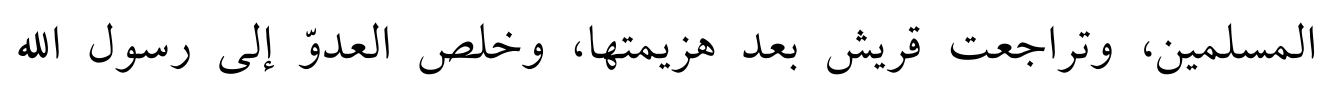

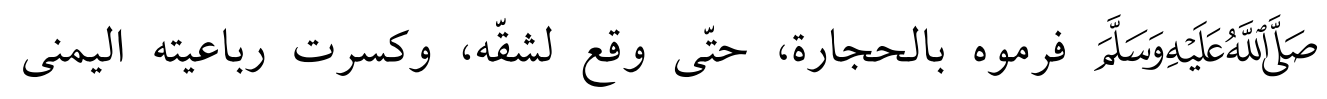

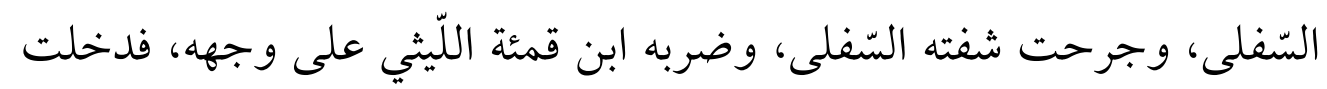

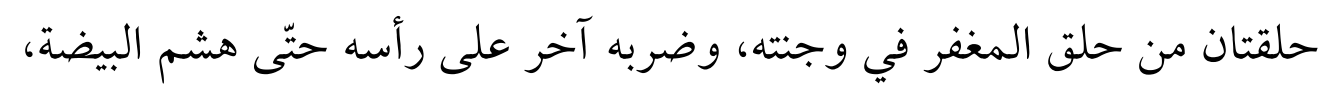

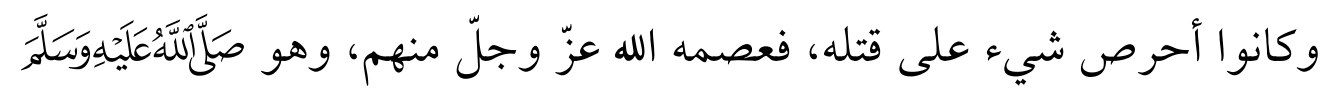

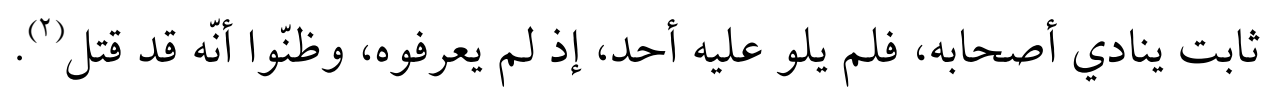
وهذا هو الظرف الدقيق الذي خارت فيه عزائم كثير من الصحابة

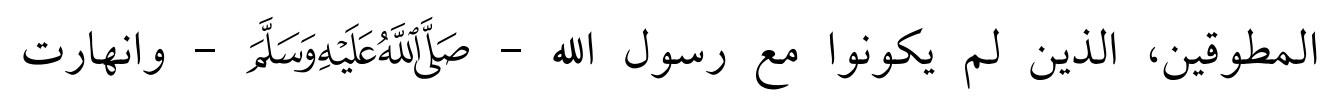

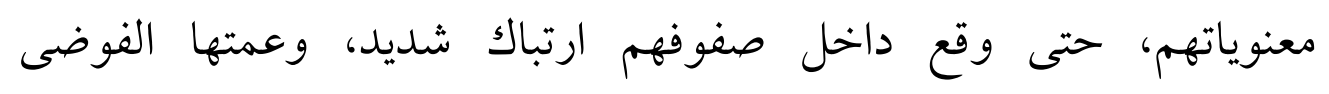
والاضطراب، إلا أن هذه الصيحة خففت بعض داخل التخفيف من مضاعفة

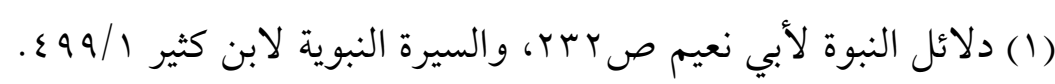

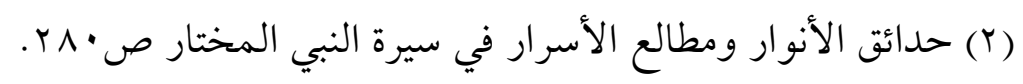


هجمات المشركين لظنهم أنهم نجحوا في غاية مرامهم، فاشتغل الكثير منهم بتمثيل قتلى المسلمين (1).

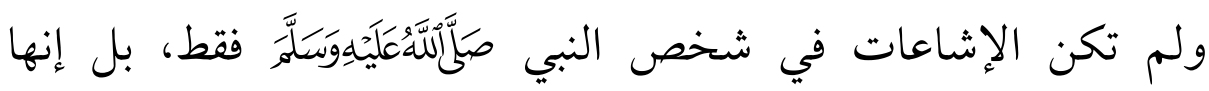

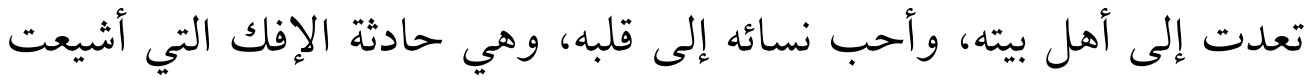

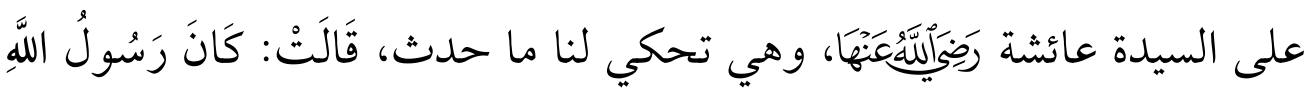

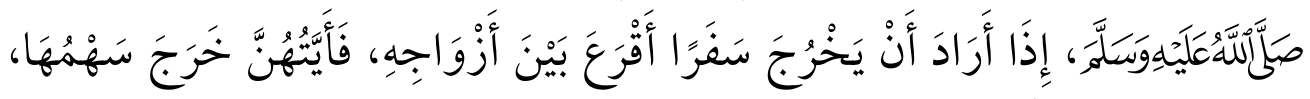

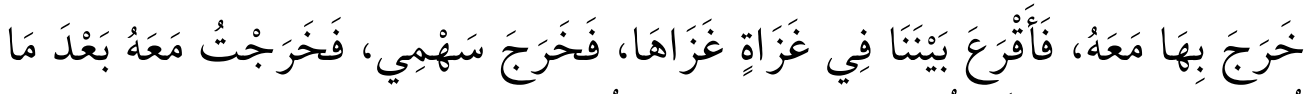

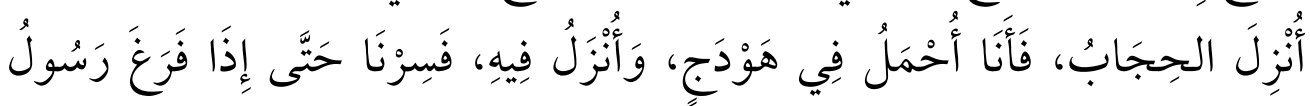

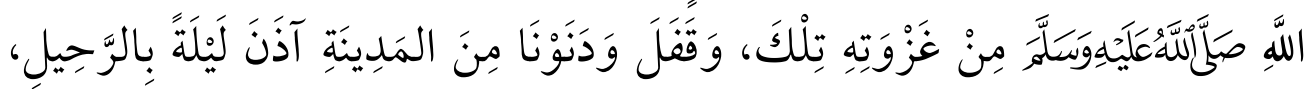

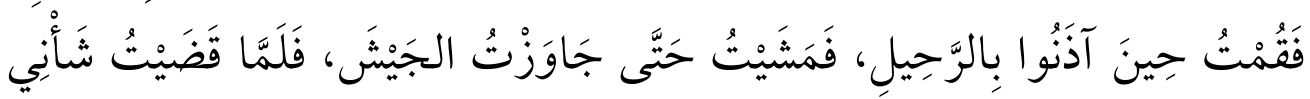

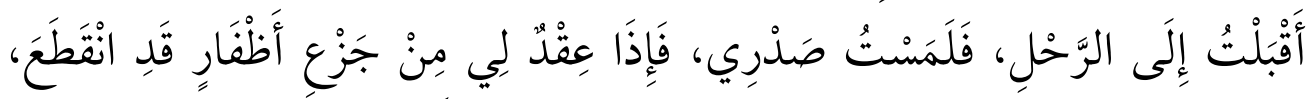

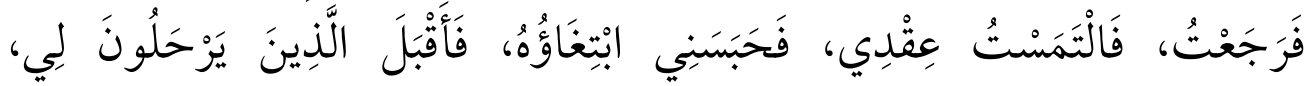

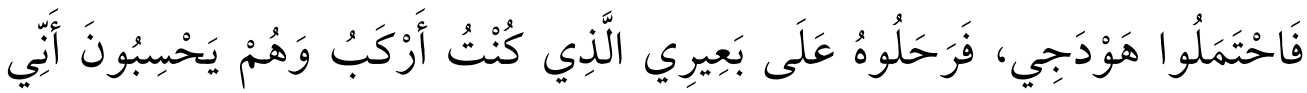

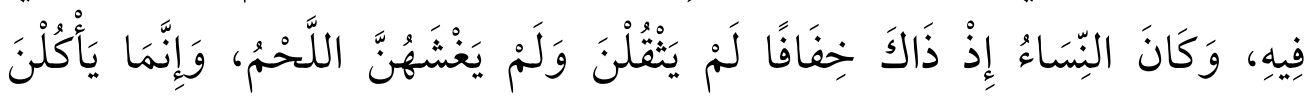

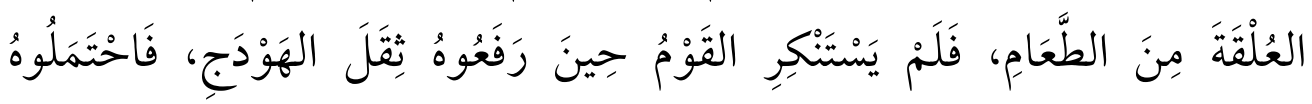

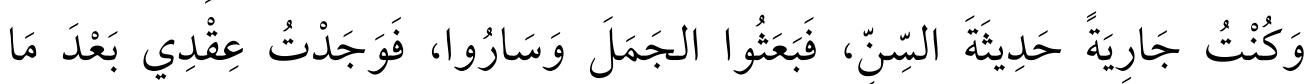

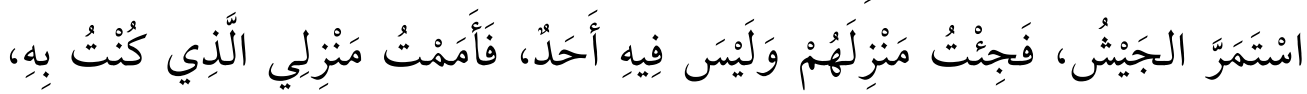

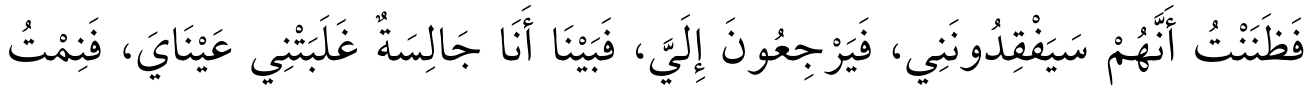

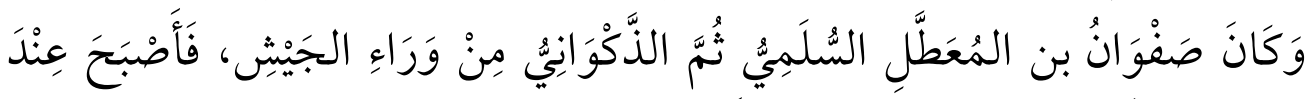

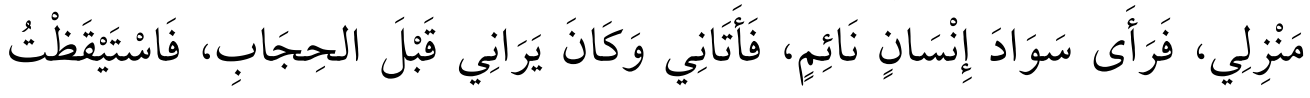

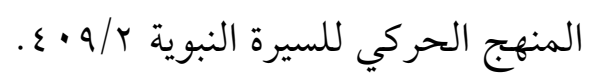




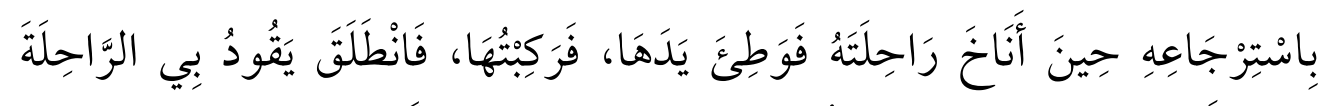

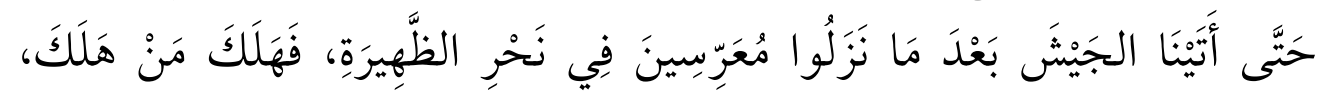

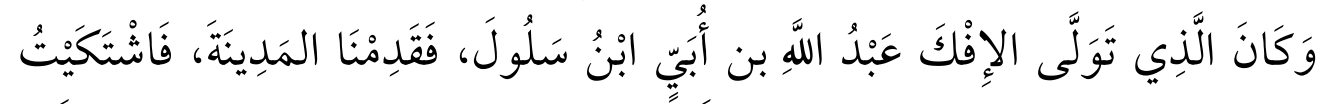

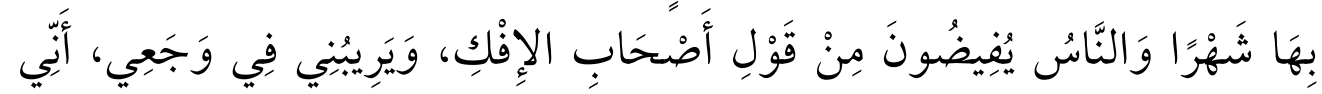

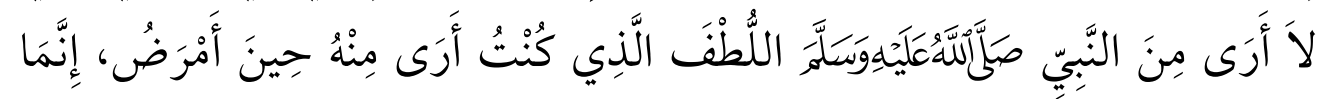

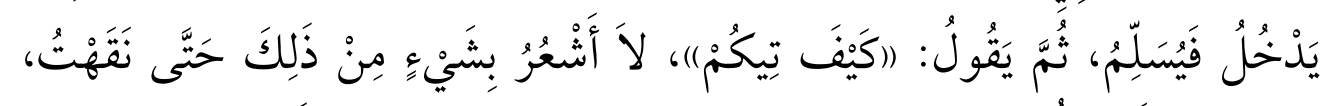

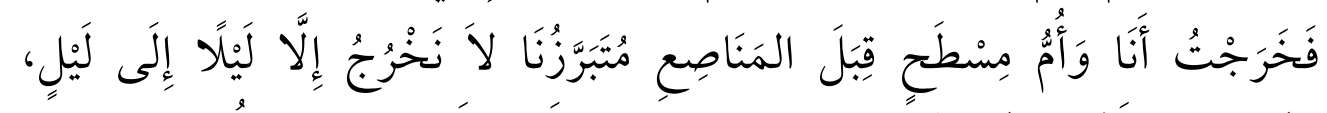

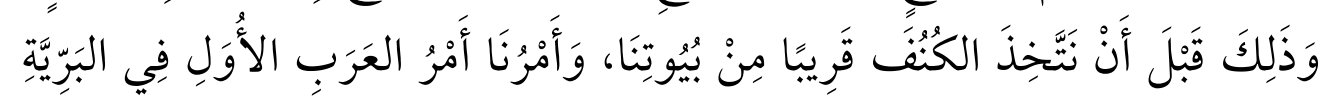

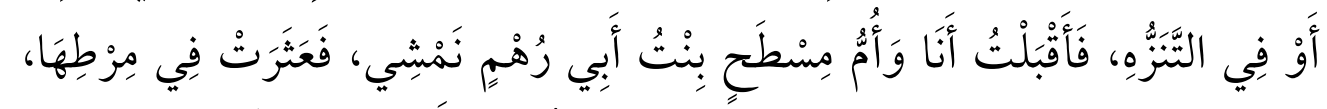

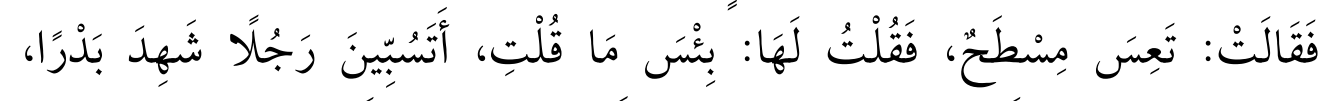

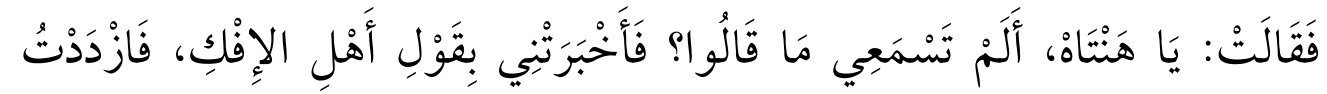

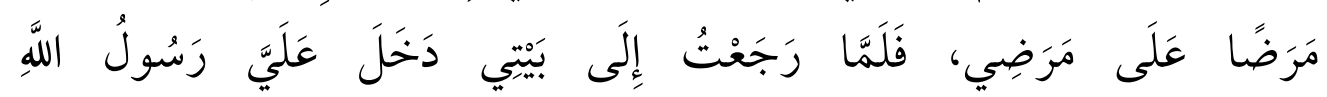

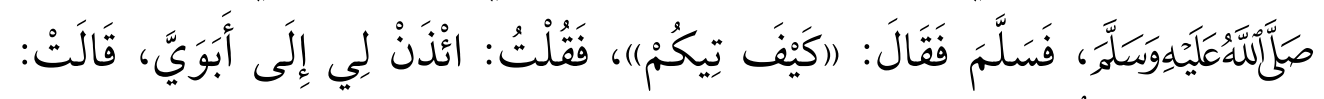

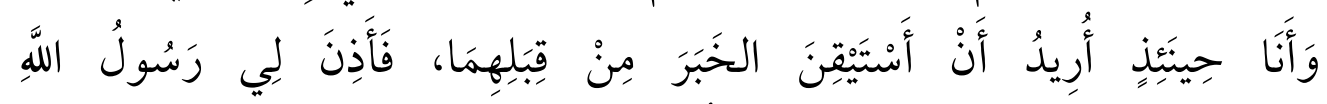

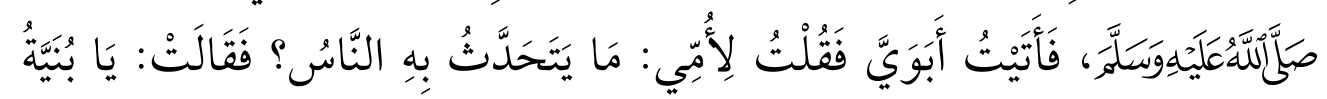

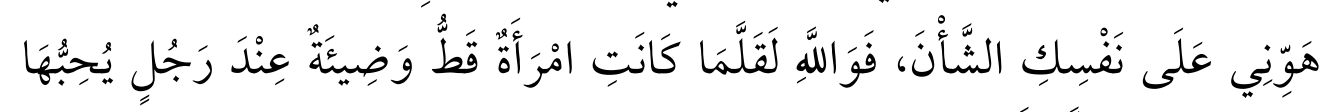

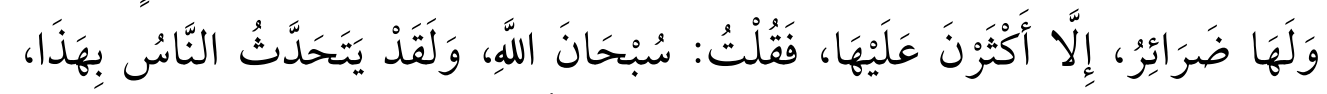

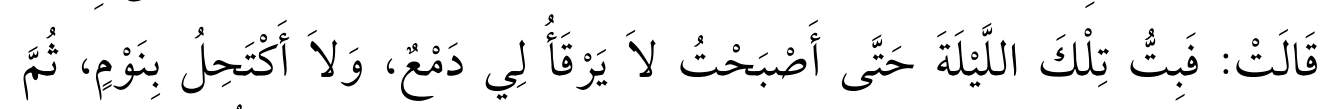

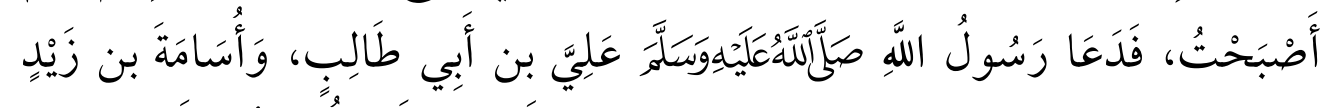

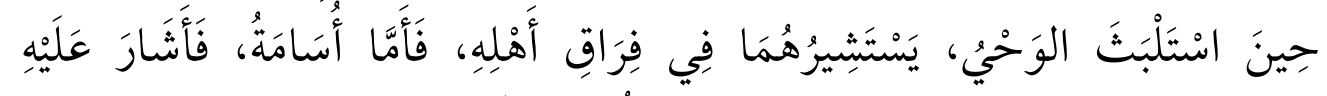

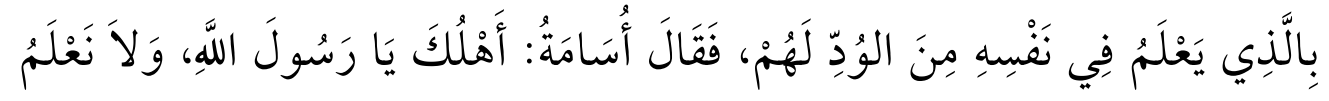




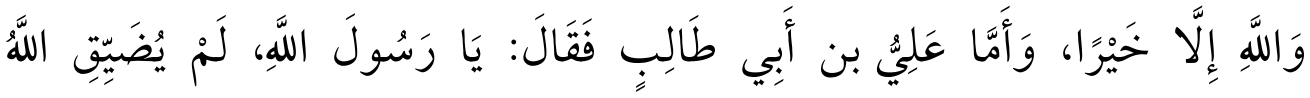

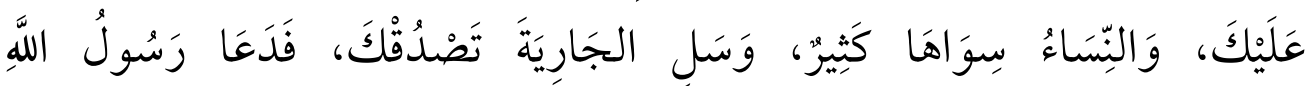

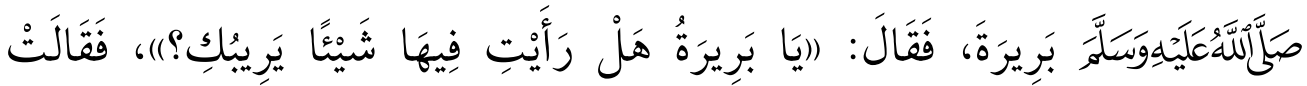

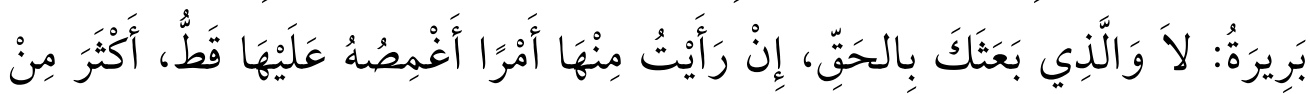

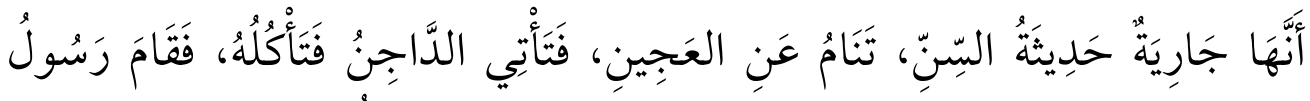

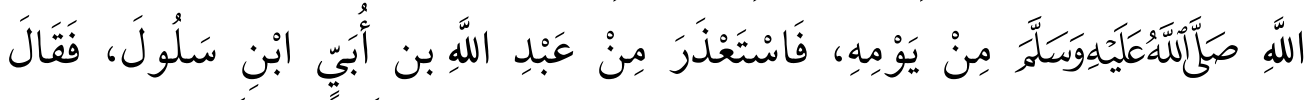

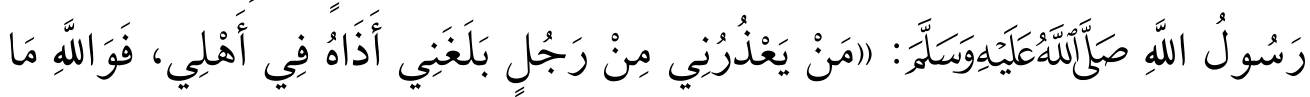

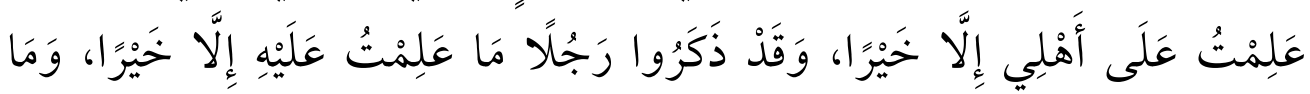

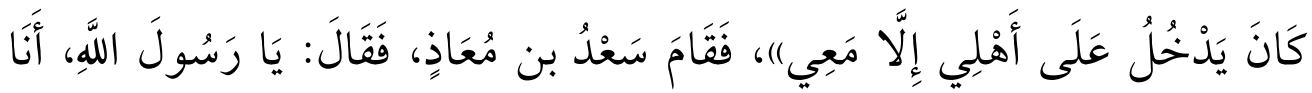

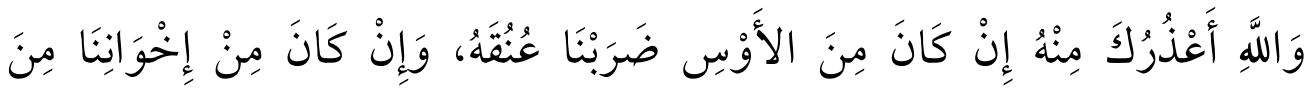

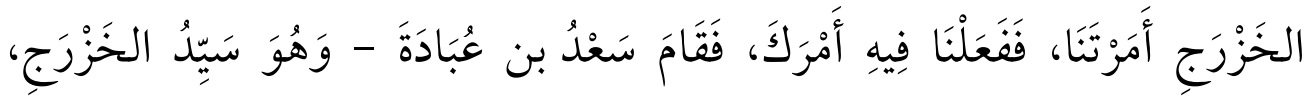

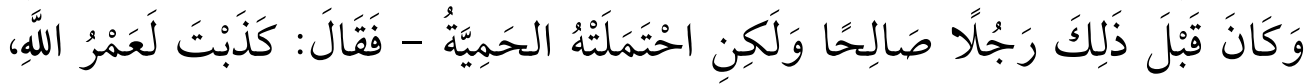

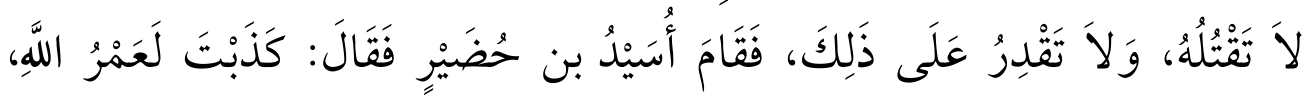

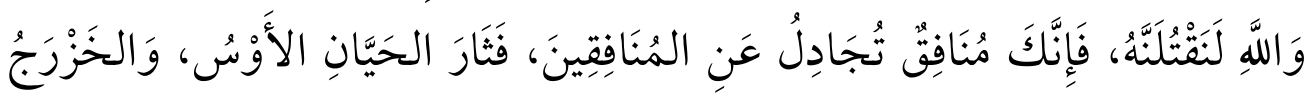

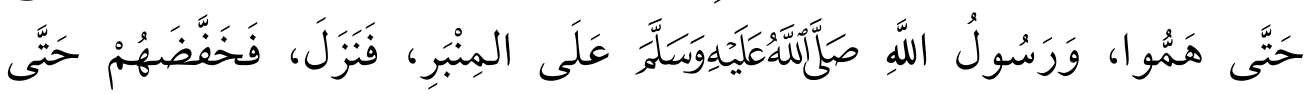

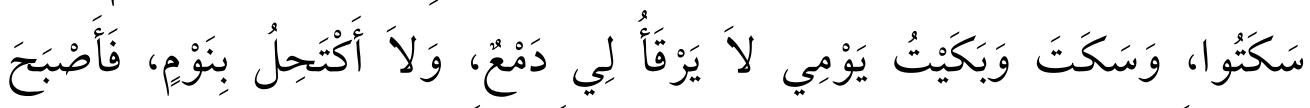

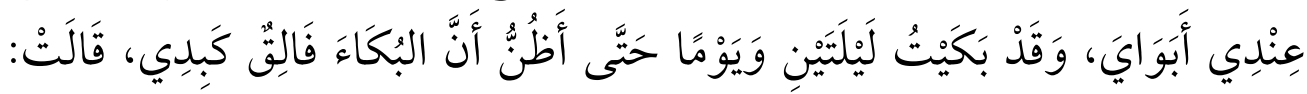

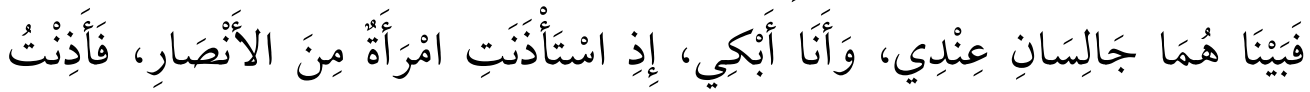

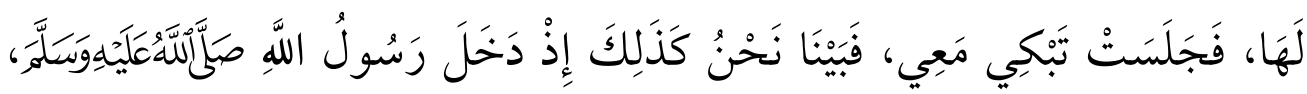

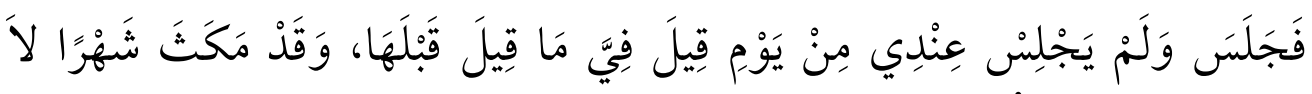

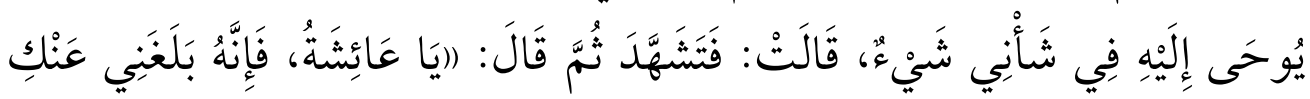




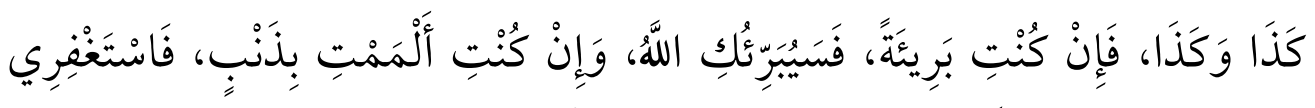

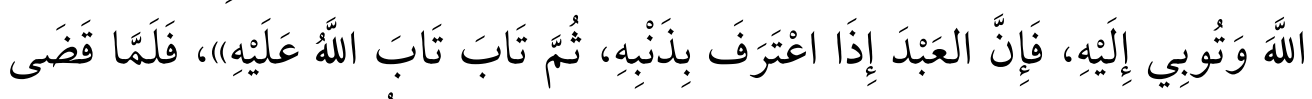

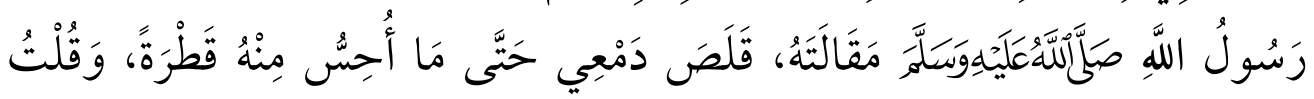

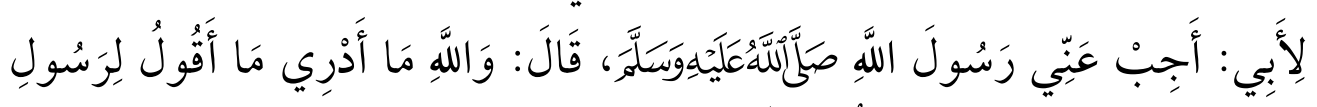

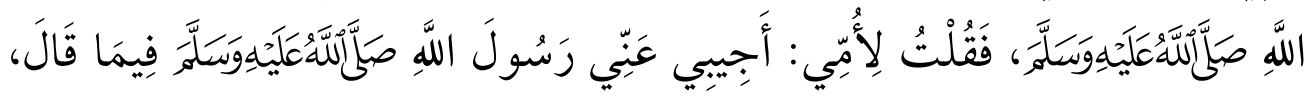

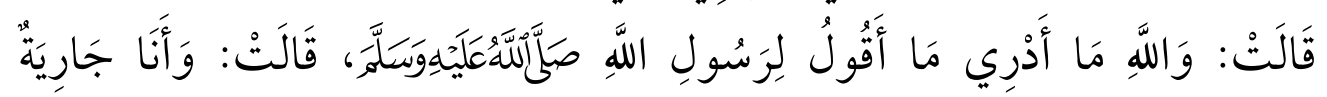

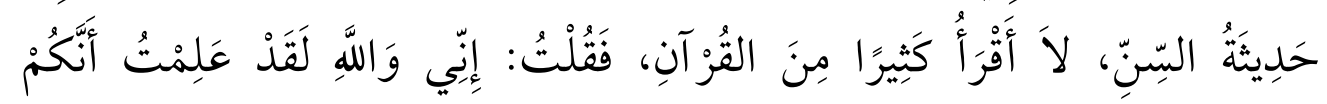

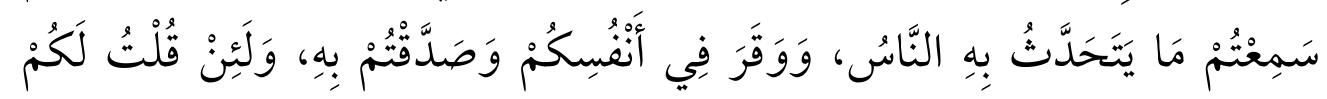

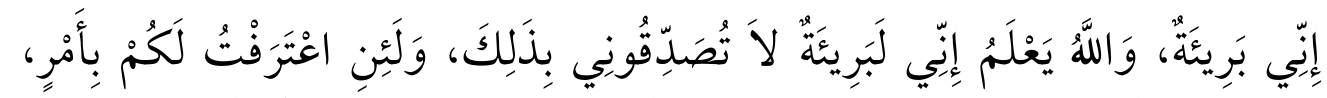

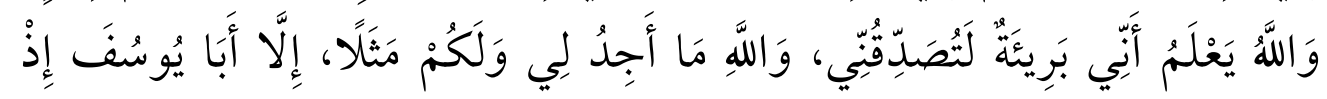

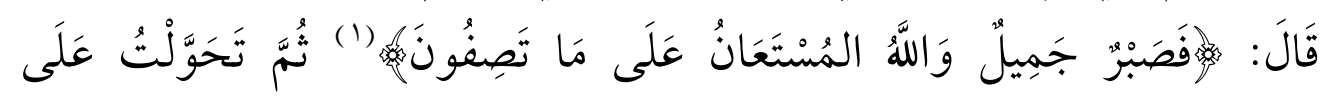

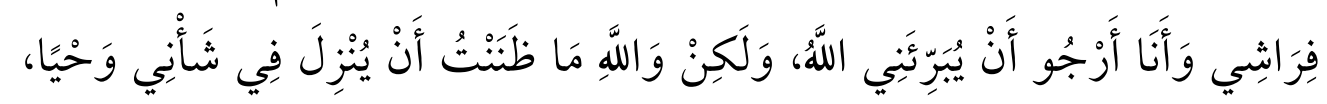

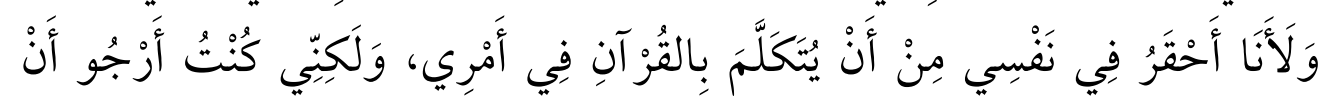

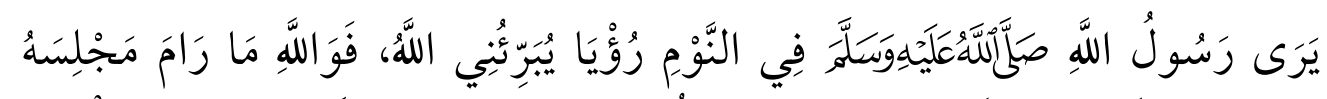

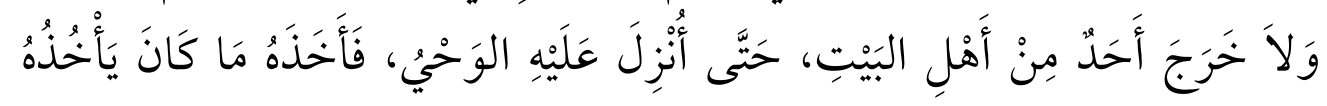

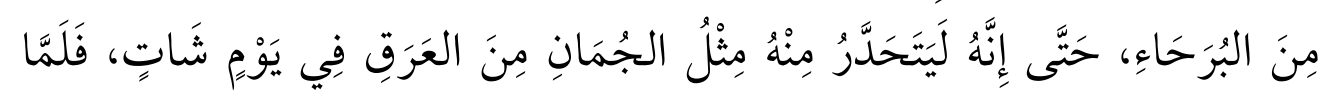

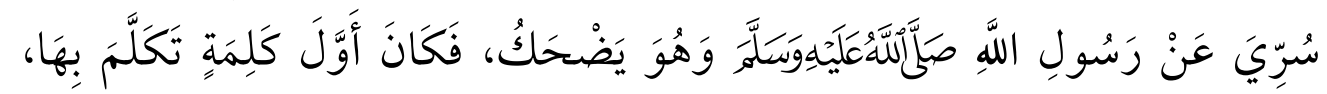

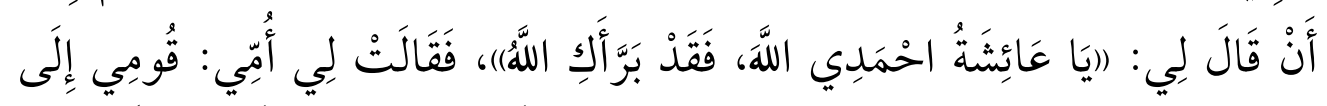

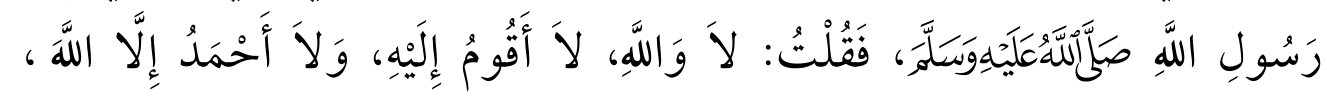

سورة يوسف، من الآية 11. 


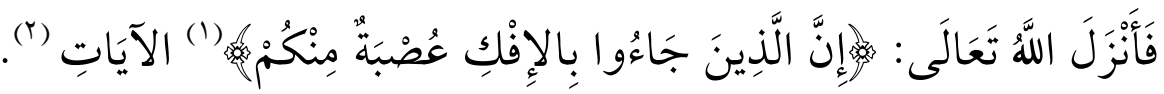

فأنزل الله تعالى براءتها من فوق سبع سماوات، وعاب على الذين

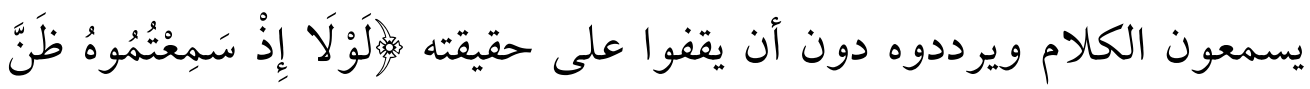

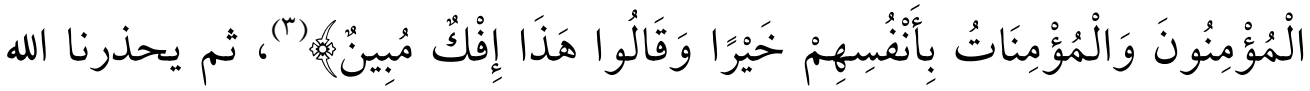

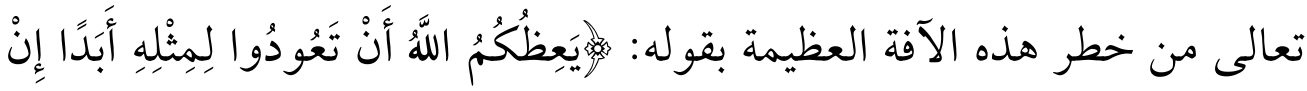

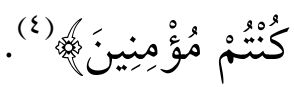

والشرع لم يترك الناس تخوض في أعراض غيرهم دون عقوبة؛ بل وضع عقوبات لمن يتكلم في أعراض الناس، ومن هذه العقوبات حد القذف، وهو ما سأتحدث عنه في المبحث التالي:

\section{G)}

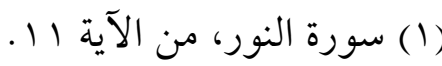

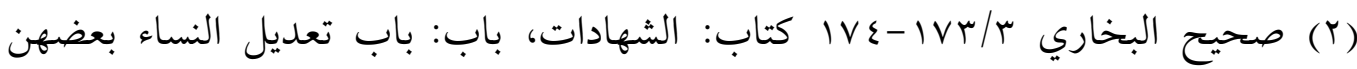

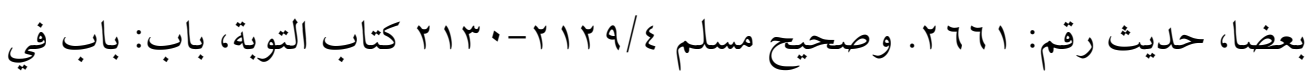

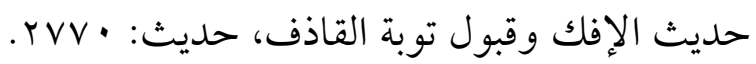

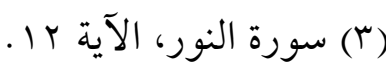

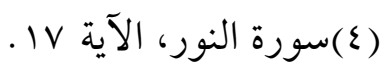




\section{المبحث الثاني}

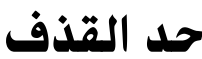

يأتي الكالام على حد القذف كمثال تطبيقي يوضح مدى عناية الإسلام بمحاربة الإشاعات والافتراءات، والكلام على حد القذف يتضمن تعريفه،

$$
\text { وأبدأ بتعريف حد القذف: }
$$

الحد لغة: الحاجز بين الشيئين، وحد الشيء منتهاه، والحد: المنع، ومنه

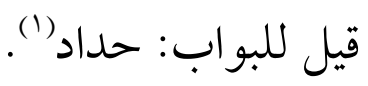

والقذف في اللغة: الرمي بالسهم والحصى والكلام وكل شيء(؟). وحد القذف اصطلاحاً: رمي مخصوص وهو الرمي بالزنا صريحا وهو القذف الموجب للحد (). وقد دل على تحريمه: الكتاب، والسنة، والإجماع.

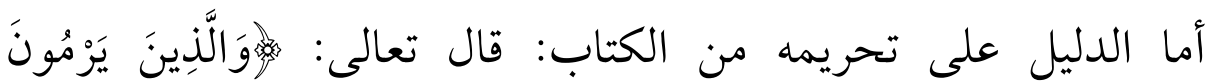

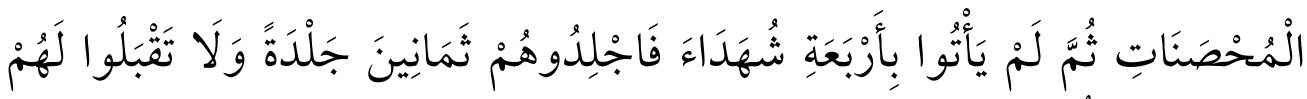

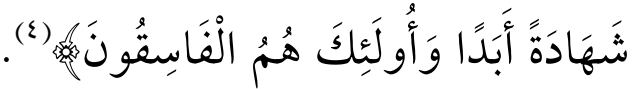

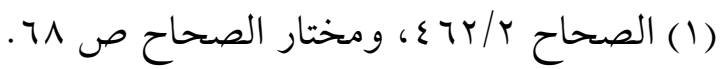

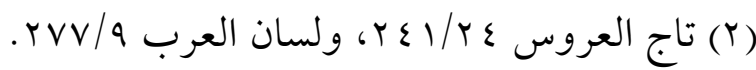

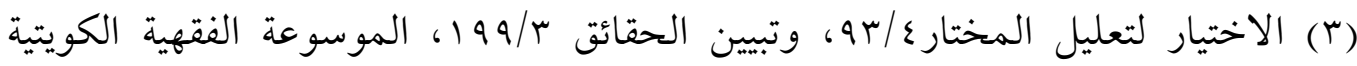

$$
\begin{aligned}
& . r V \cdot / r I \\
& \text { سورة النور، آية ع. }
\end{aligned}
$$


يعني الذين يرمون المحصنات العفيفات الحرائر ثم لم يأتوا بأربعة

شهداء يشهدون على كلامهم فاجلدوهم ثمانين جلدة" (1).

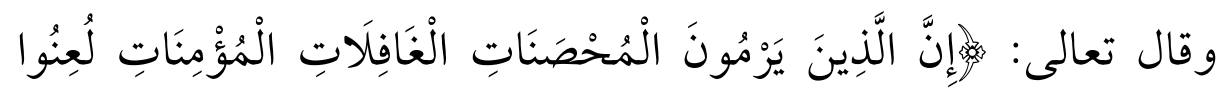

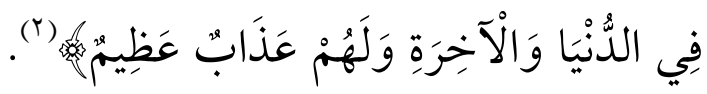

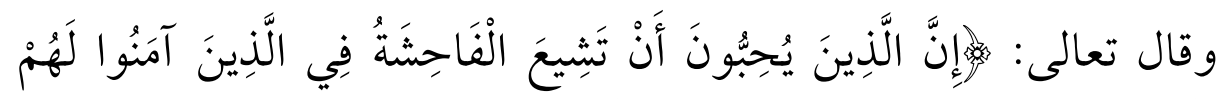

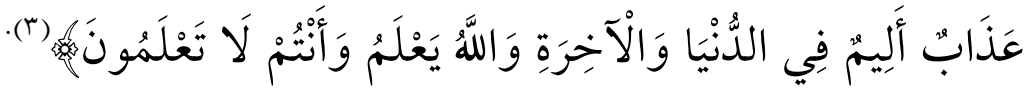

فكل هذه الآيات توضح حرمة القذف وأن الله تعالى جعل الجلد في الدنيا والوعيد في الآخرة لمن يتكلم في أعراض الناس. والدليل على حرمة القذف من السنة:

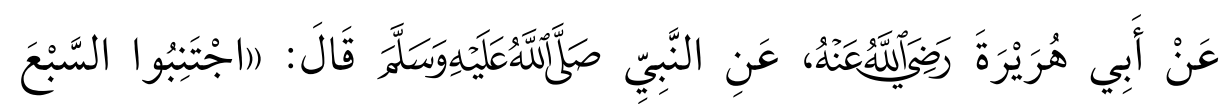

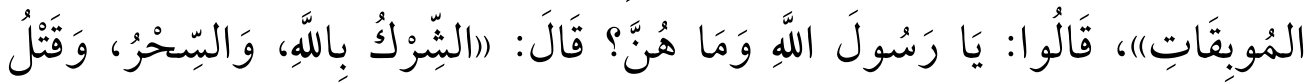

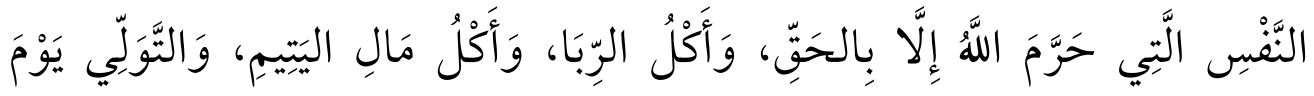

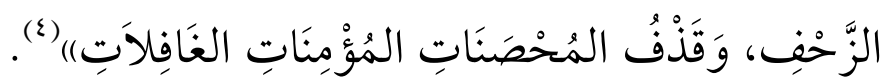

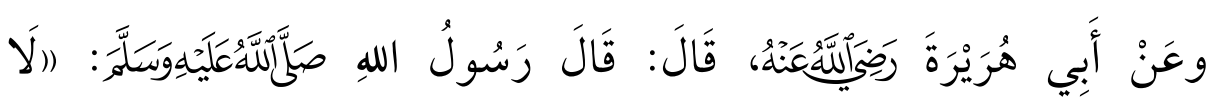

$$
\begin{aligned}
& \text { (1) تفسير البغوي } 1 \text { / • . }
\end{aligned}
$$

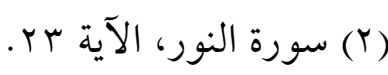

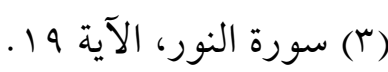

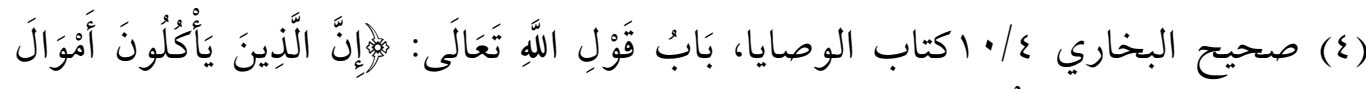

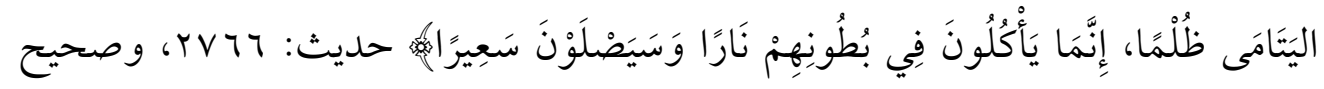

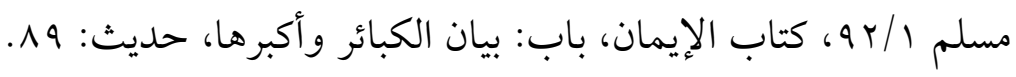




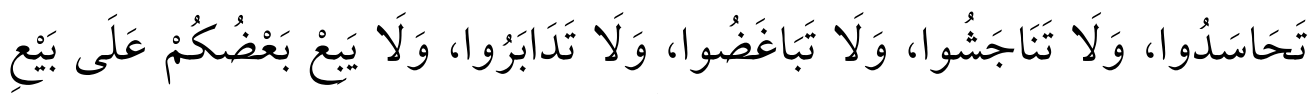

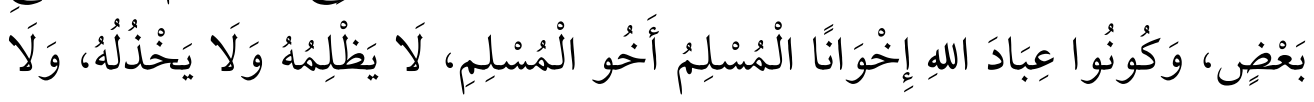

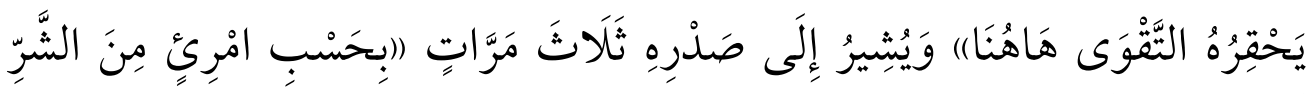

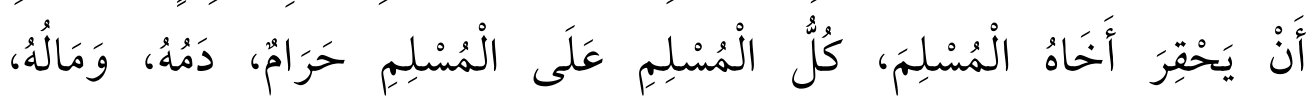

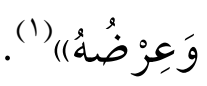

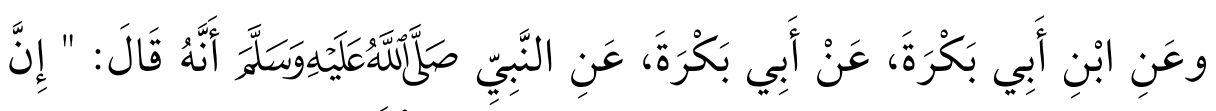

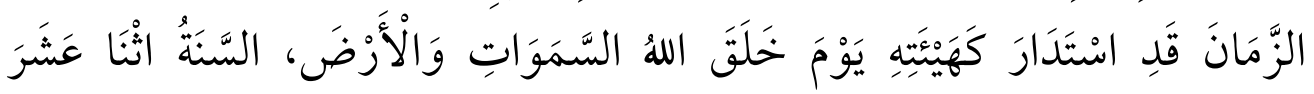

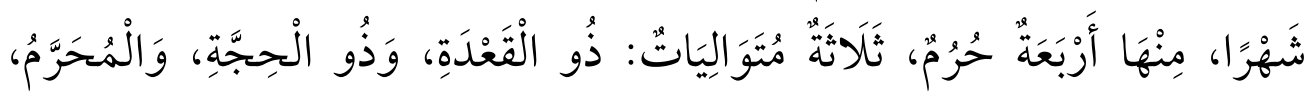

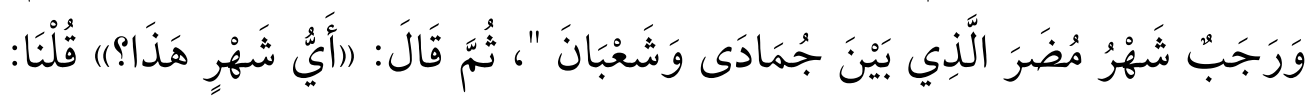

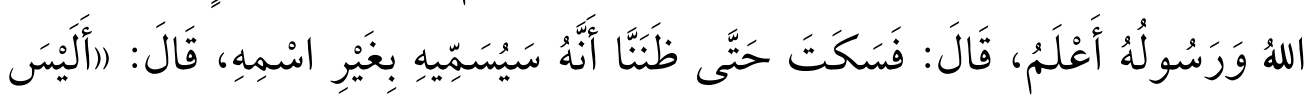

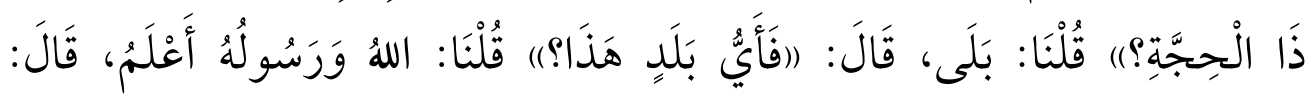

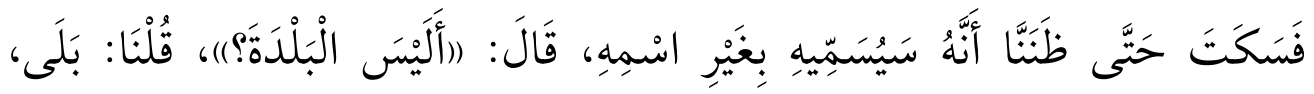

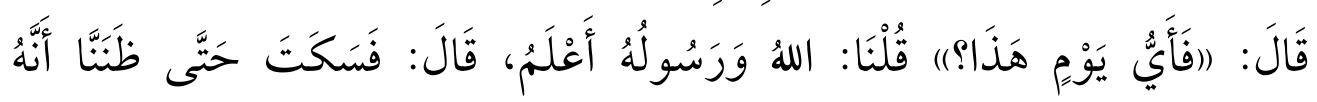

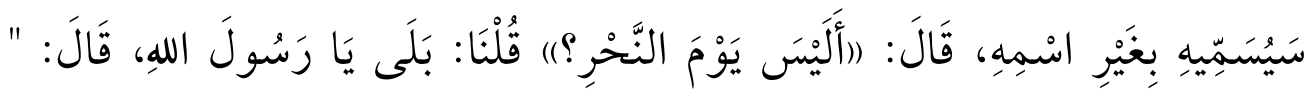

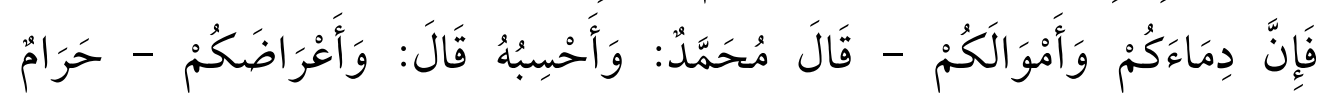

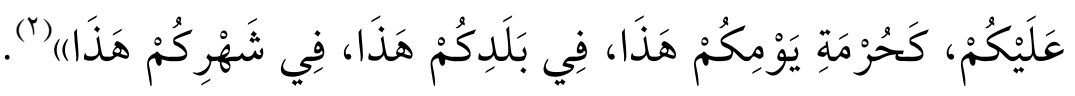

(1) صحيح مسلم ع/71911 كتاب البر والصلة، باب تحريم ظلم المسلم، وخذله، واحتقاره

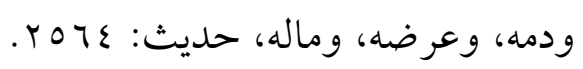

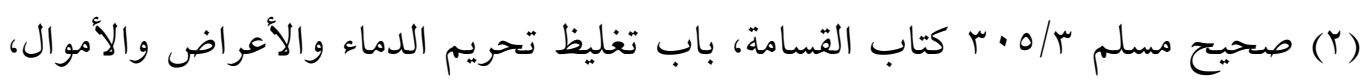
حديث: 17V9. 
وأجمعت الأمة على حرمة القذف وأنه من الكبائر (1).

ما يشترط في القذف: للقذف شروط لابد من توافرها حتى يصبح جريمة تستحق عقوبة الجلد.

وهذه الشروط منها ما يجب توافره في القاذف، ومنها ما يجب توافره في المقذوف، ومنها ما يجب توافره في الشيء المقذوف به. شروط القاذف: - ( والشروط التي يجب توافرها في القاذف هي:

$$
\begin{aligned}
& 1 \text { - العقل. } \\
& \text { r - البلوغ. } \\
& \text { r - الاختيار. }
\end{aligned}
$$

لان ذلك أصل التكليف، ولا تكليف بدون هذه الاشياء.

شروط المقذوف: - مقا:

$$
\text { وشروط المقذوف هي: }
$$

1 - العقل: لان الحد إنما شرع للزجر عن الاذية بالضرر الواقع على المقذوف، ولا مضرة على من فقد العقل فلا يحد قاذفه.

r - البلوغ: وكذلك يشترط في المقذوف البلوغ، فلا يحد قاذف الصغير و الصغيرة.

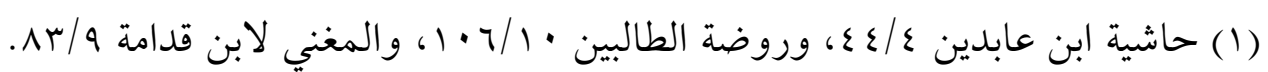


r - الإسلام: والاسلام شرط في المقذوف، فلو كان المقذوف من غير المسلمين لم يقر الحد على قاذفه عند جمهور العلماء.

ع - العفة: وهي العفة عن الفاحشة التي رمي بها سواء أكان عفيفا عن غيرها

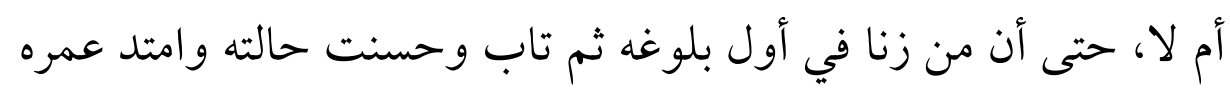
فقذفه قاذف، فإنه لا حد عليه.

وإن كان هذا القذف يستوجب التعزير لأنه أشاع ما يجب ستره وإخفاؤه.

ما يجب توفره في المقذوف به: أما ما يجب توفره في المقذوف به،

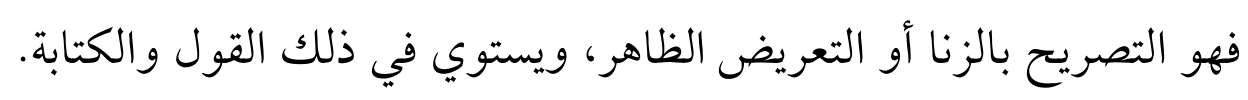

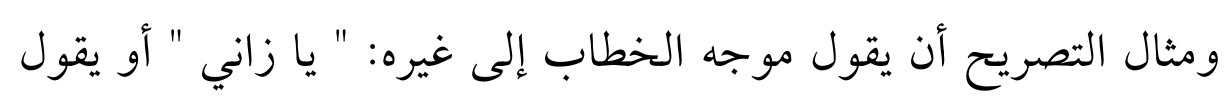
عبارة تجري مجرى هذا التصريح، كنفي نسبه عنه.

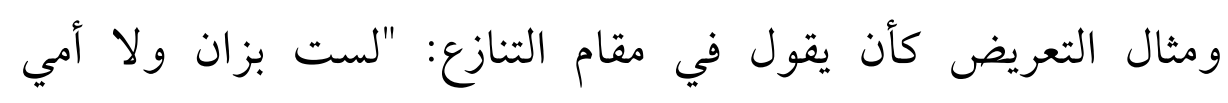

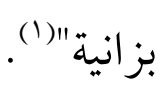
هذا وهناك شروط مختلف فيها بين الفقهاء لا مجال لذكرها.

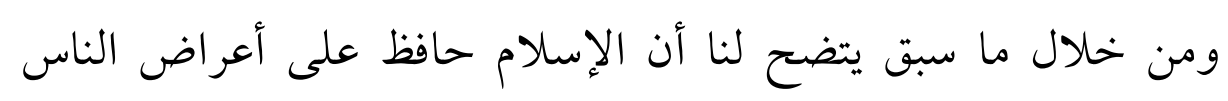

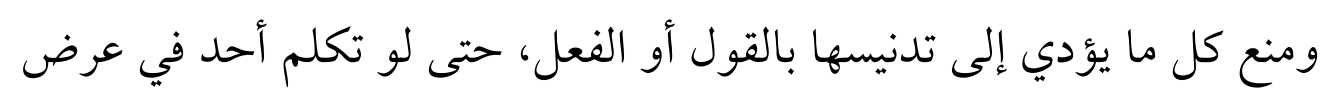

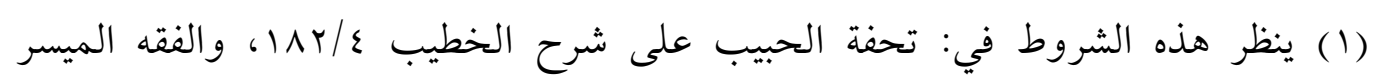

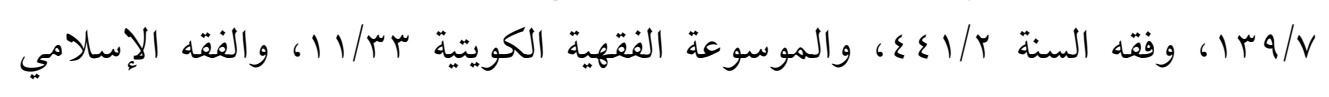

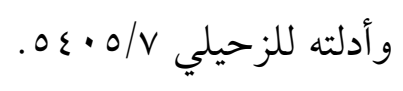


أخيه فإما أن يكون مع شهود على ذلك أو أنه يقام عليه حد القذف، كما قال

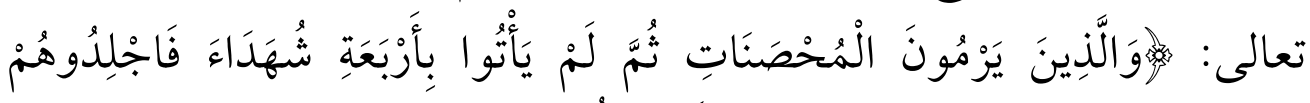

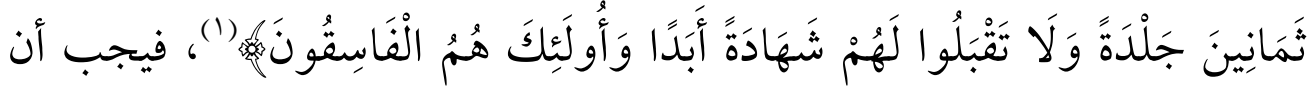

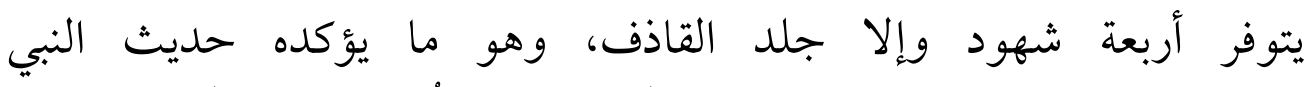

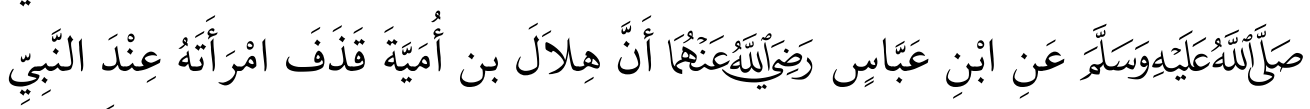

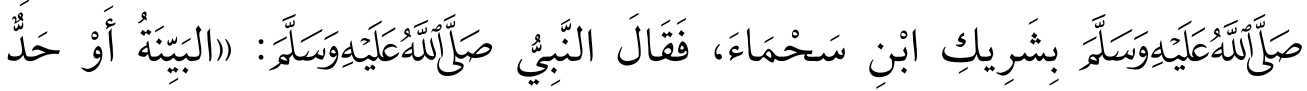

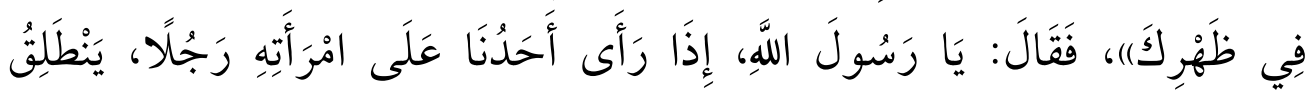

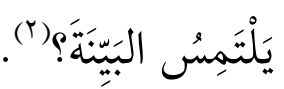

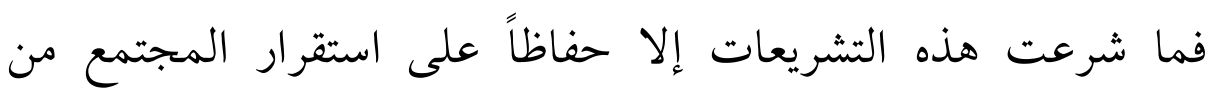

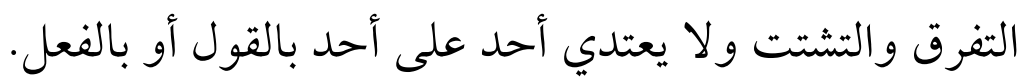

\section{G)}

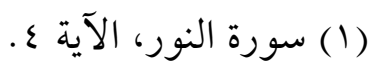

(r) صحيح البخاري r/r/r/r) كتاب الشهادات، باب إذا ادعى أو قذف، فله أن يلتمس البينة،

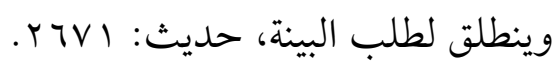




\section{المبحث الثالث}

\section{منهج الإسلام في التعامل مع الشائعات}

لقد وضع الإسلاجُ ضوابطَ للتعامل مع مثل هذه الأخبار، ولم يترك الناس إلا ورسم الطريق الصحيح الذي يوصل بالإنسان إلى بر الأمان، ومن هذه الضو ابط ما يأتي:

أولا: التثبت من الخبر قبل نقله وإشاعته، فإن الإنسان إذا تثبت من الخبر قبل الحكم عليه فإنه يسلم من كثير من العواقب التي تؤدي إلى الندم بعد ذلك، وقد لا ينفع الندم بعد صدور الحكم من الشخص، وفي

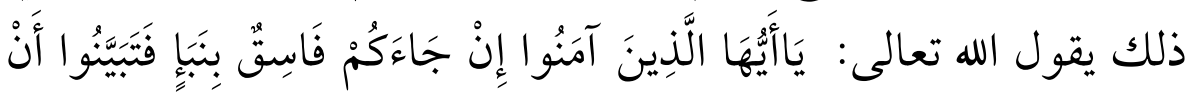

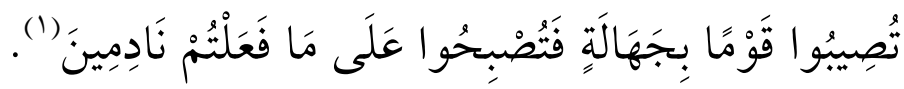
فهذا نداء للمؤمنين يدعوهم إلى التحلي بهذه الصفة الحميدة، وكيف أن المؤمن إذا امثثل أمر الله فاز في الدنيا والآخرة، وإذا لم يمتثل خسر الدنيا والآخرة، وما أجمل التعبير القرآني حيث قال: فتصبحوا على ما فعلتم نادمين.

ونبينا صَلَّلَّلَّهَعَيَّدوَسَلَّمَ يضرب لنا أروع الأمثلة في التثبت وعدم التسرع في صدور الحكم، كما جاء في حادثة الإفك، ولك أن تتخيل رجل يؤذى في

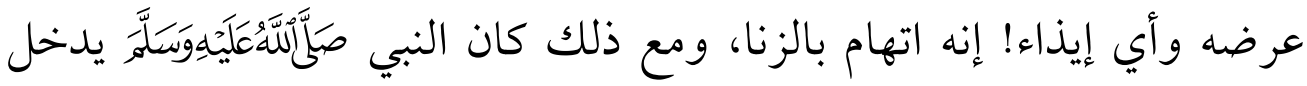

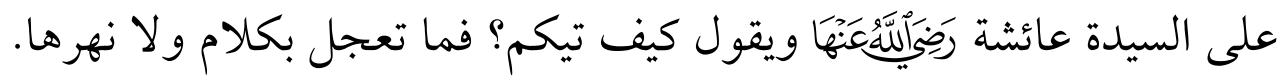


وفي هذا المعنى أيضاً ما جاء من أن هذه الآية نزلت في الوليد بن

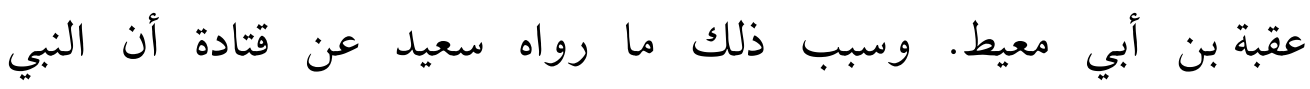

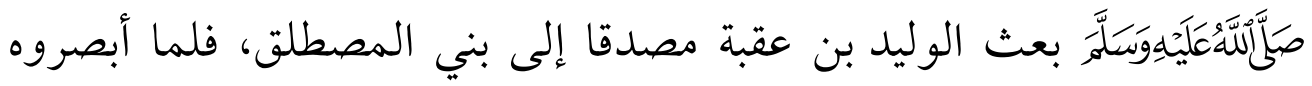

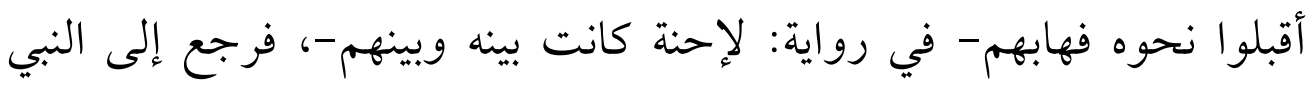

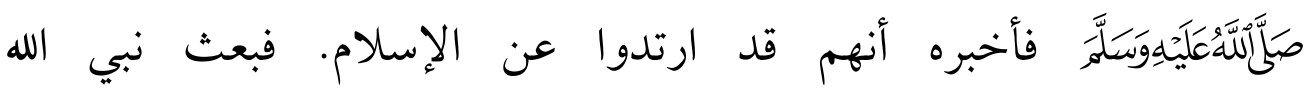

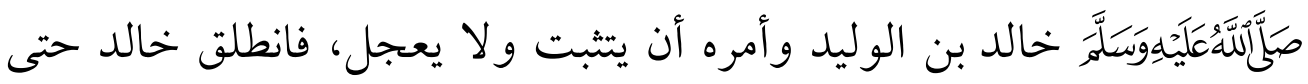

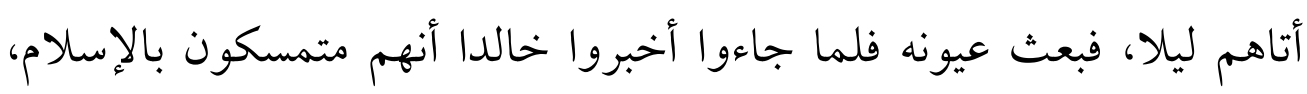

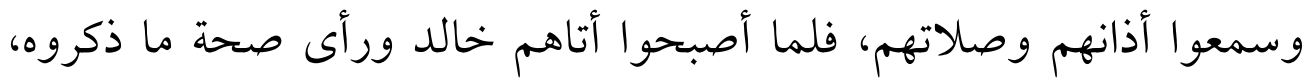

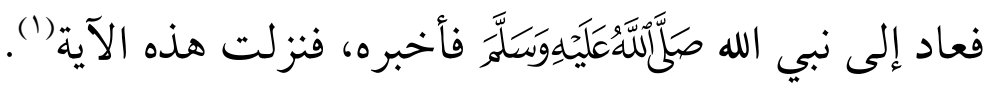

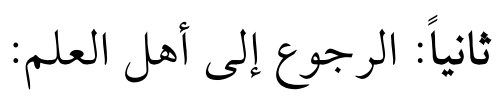
إن الله تبارك وتعالى أمرنا بالرجوع إلى العلماء، قال تعالى: وَإِذَا جَاءَهُمْ

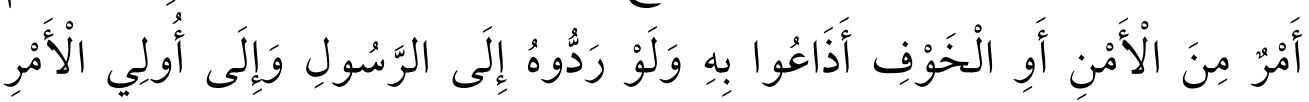

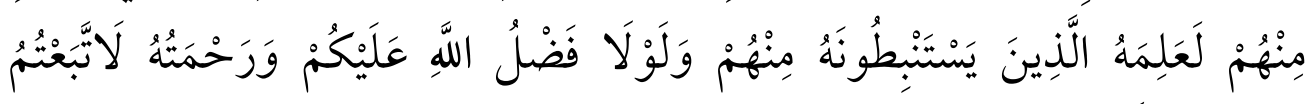

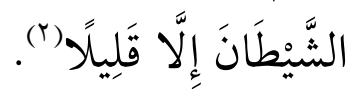

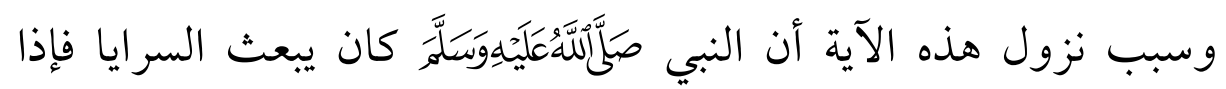

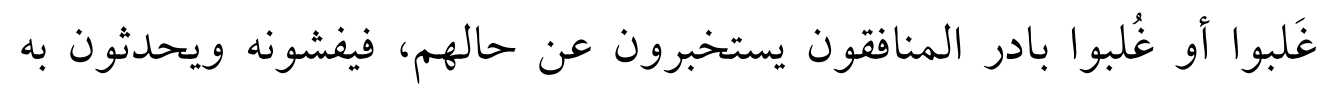

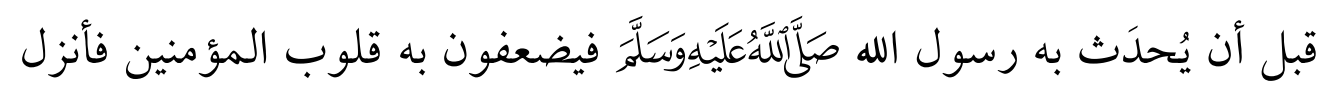

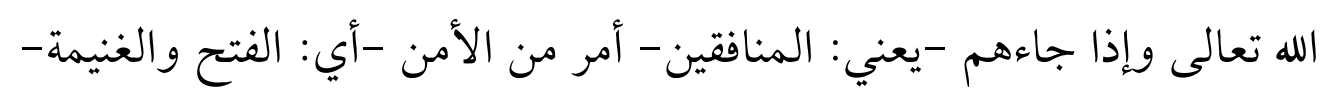


أو الخوف والقتل والهزيمة- أذاعوا به أشاعوه وأفشوه، ولو ردوه إلى الرسول

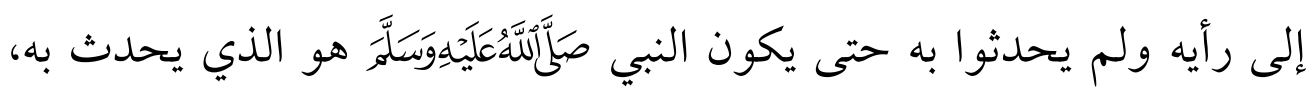

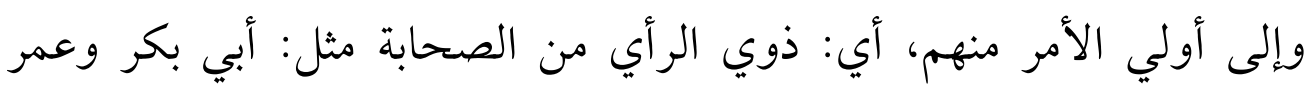

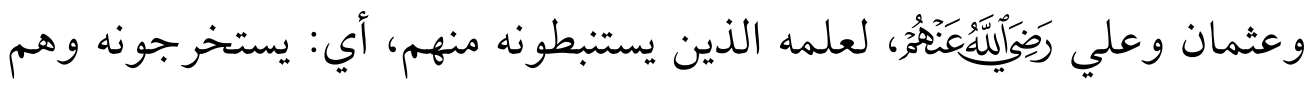

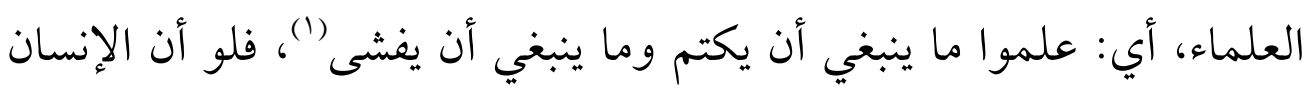

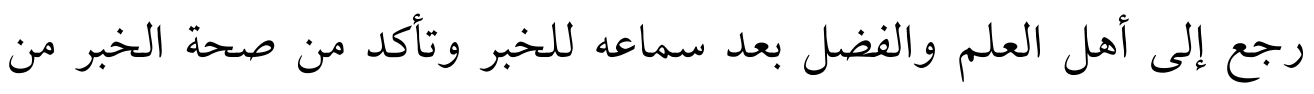
عدمه لما ترتب على ذلك أضرار بل إنه يفوز في الدارين إن شاء الله. ثالثاً: أن يستعمل الإنسان عقله للوصول إلى الحقيقة، فالله تعالى ميّز الإنسان

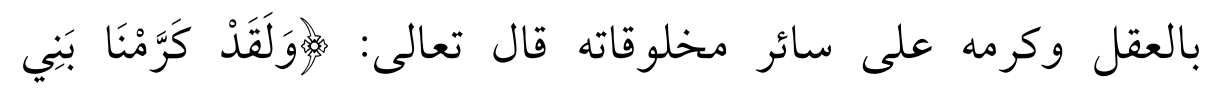

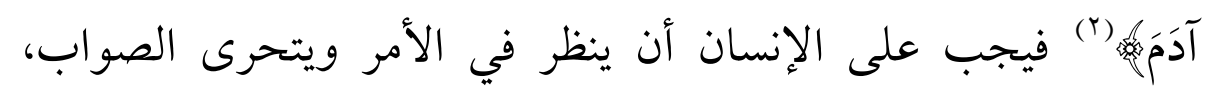

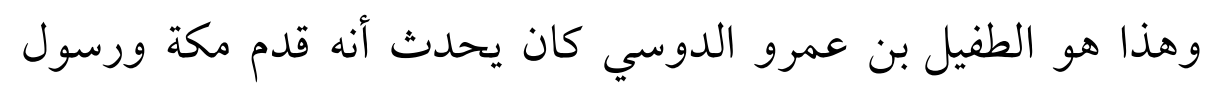

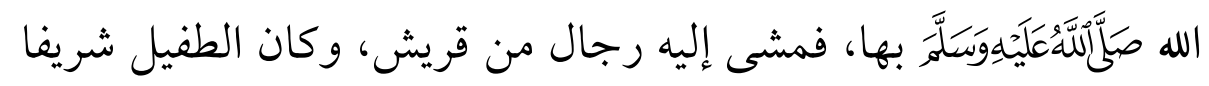

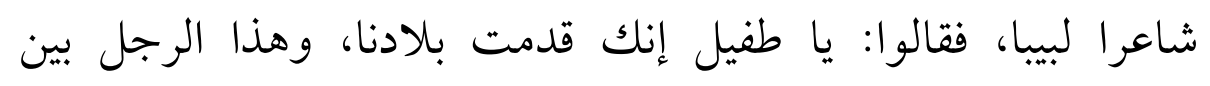

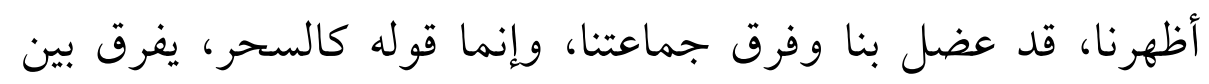

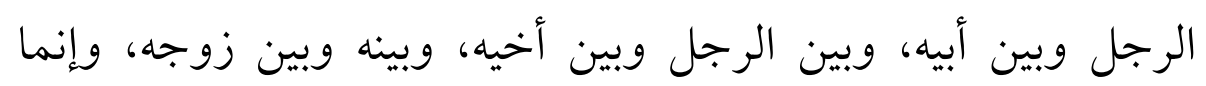

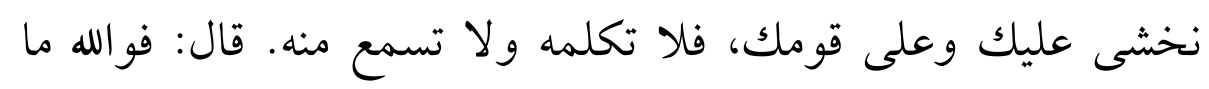

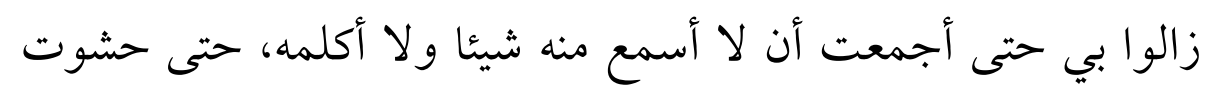

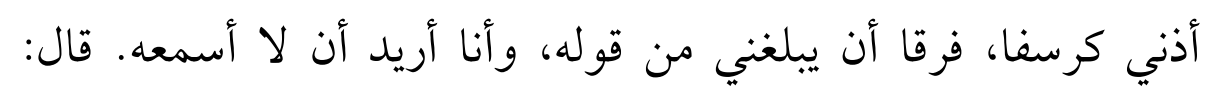

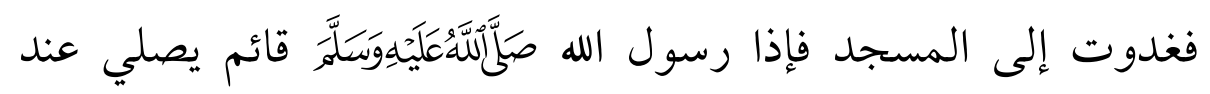

$$
\begin{aligned}
& \text { (1) تفسير البغوي= معالم التنزيل في تفسير القرآن /TVV/ (1) }
\end{aligned}
$$

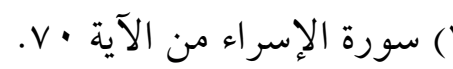


الكعبة، قال: فقمت قريبا منه، فأبى الله إلا أن يسمعني قوله، فسمعت

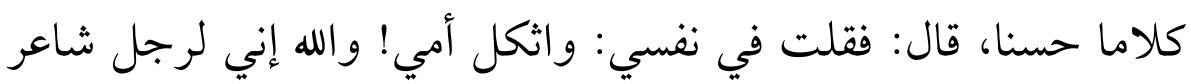

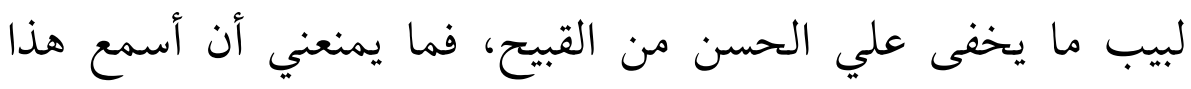

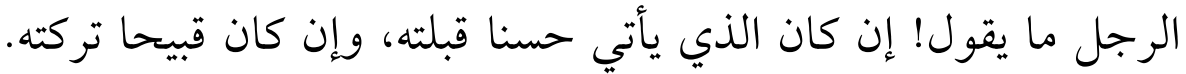

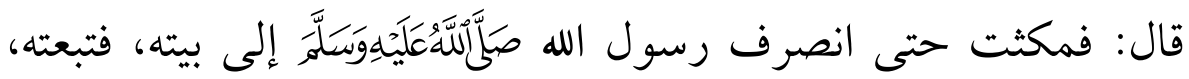

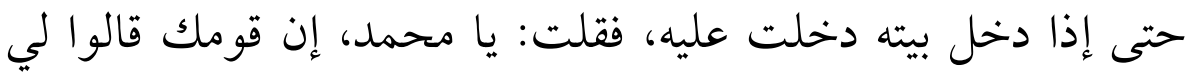

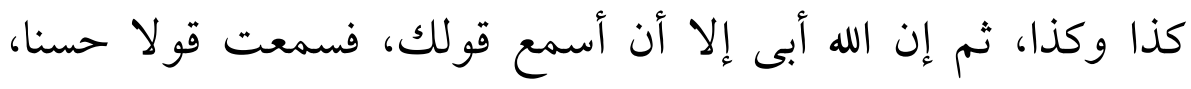

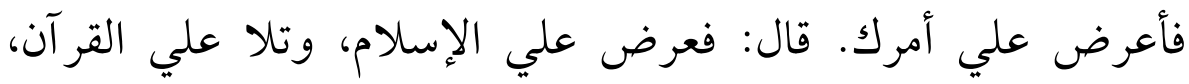

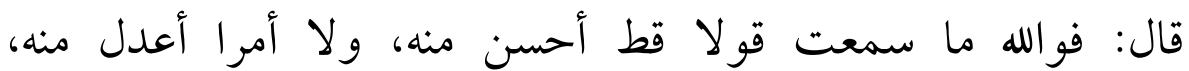

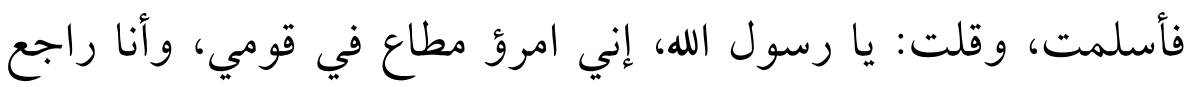

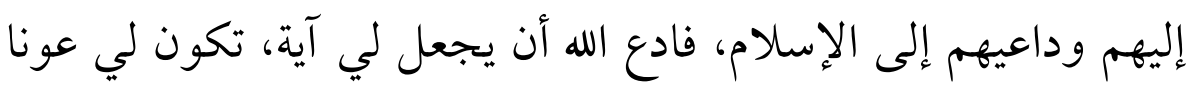

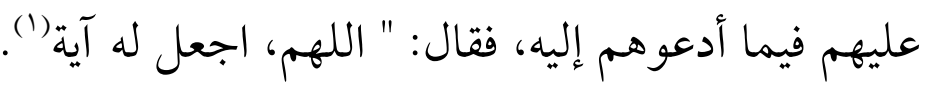
رابعاً: وضع الشرع عقوبة أخروية لمن لا يتبت من صحة الكلام:

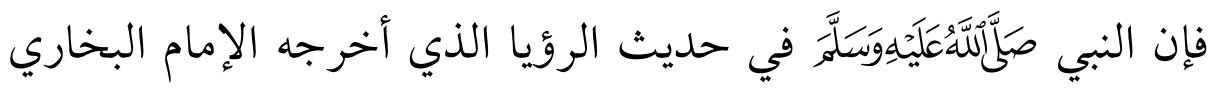

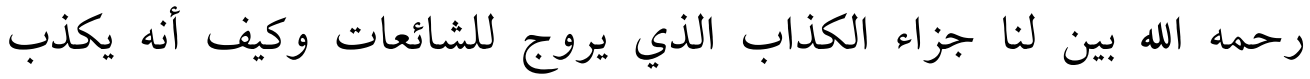

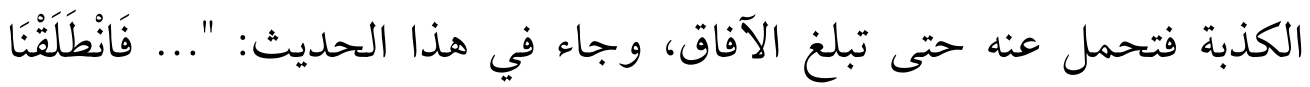

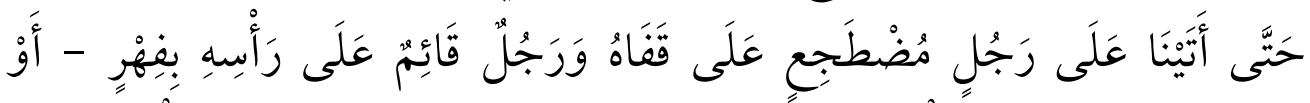

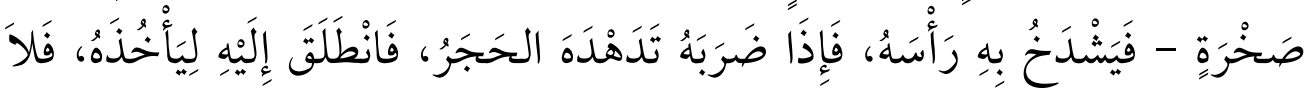

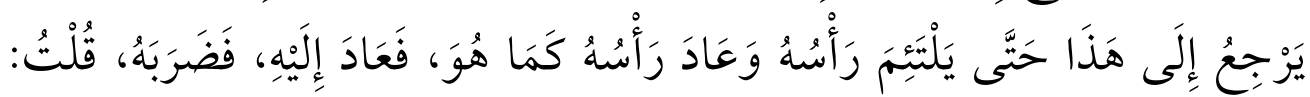




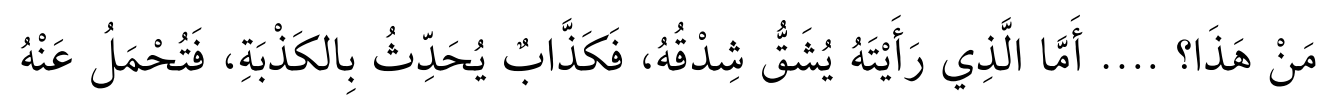

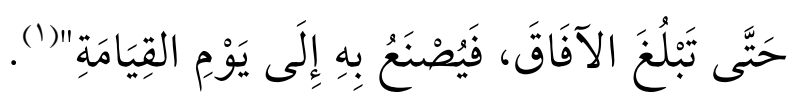

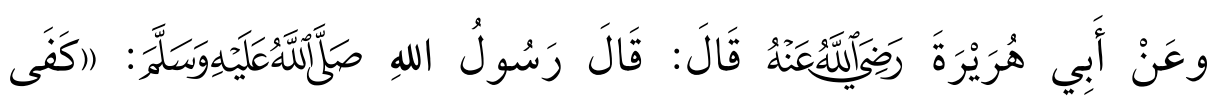

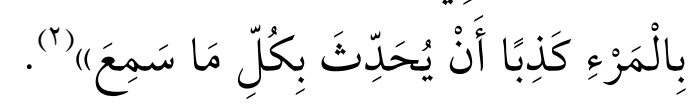

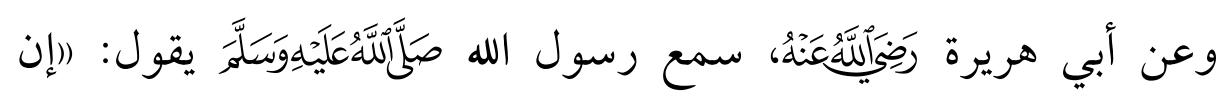

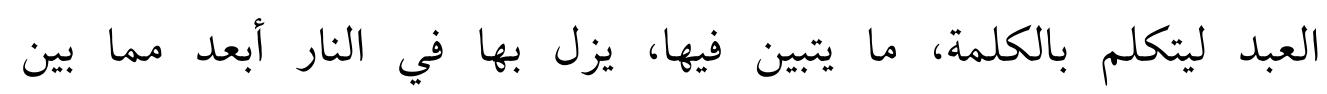

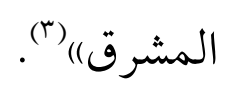

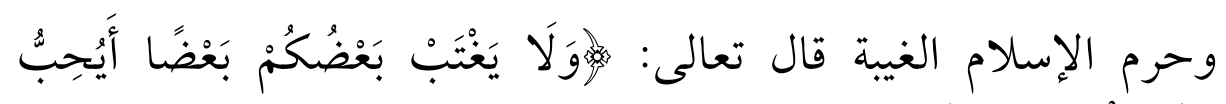

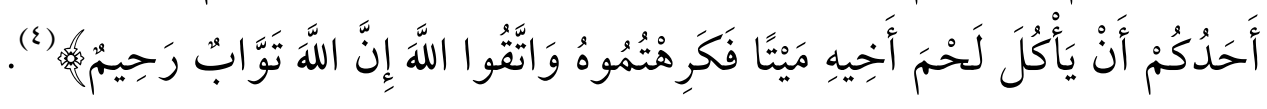

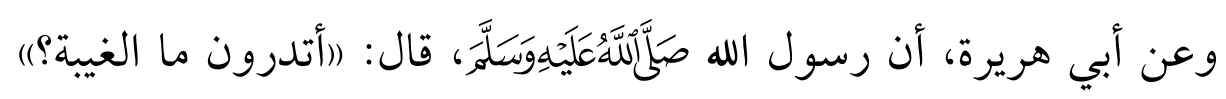

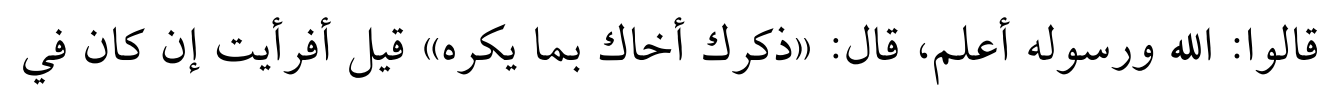

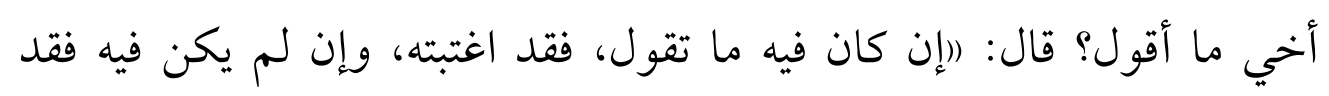

بهن

الإشاعات في نظر القانون:

ولم ينس القانون المصري عقوبة من يروج للإشاعات بقصد تكدير

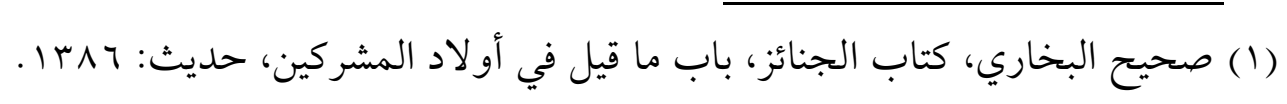

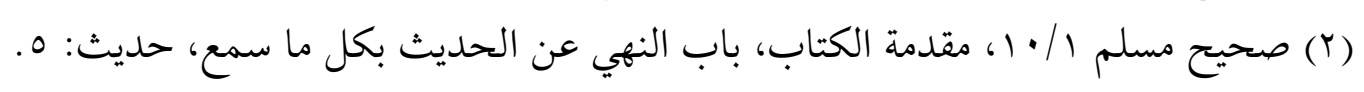

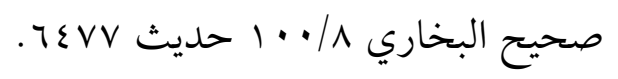

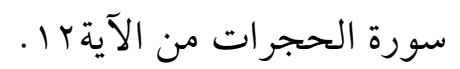

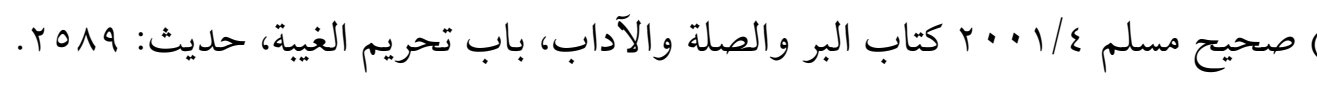


السلم العام، ويعكر صفو البلاد، لأن خطر الإشاعة أشد من خطر الحرب

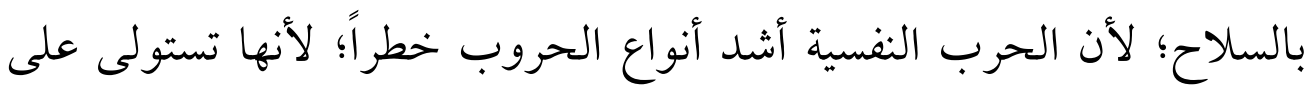

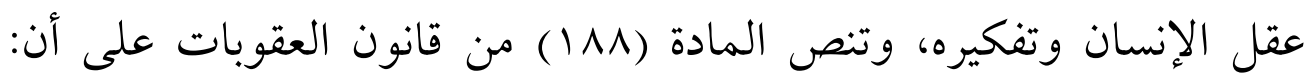

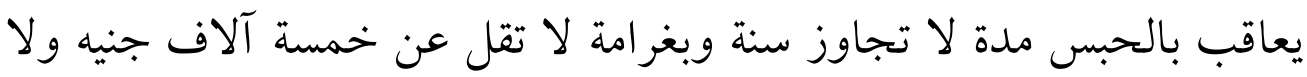

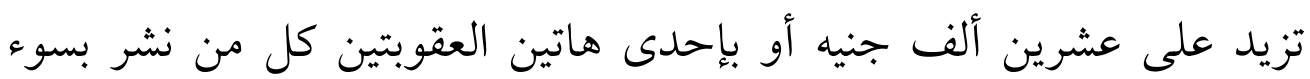

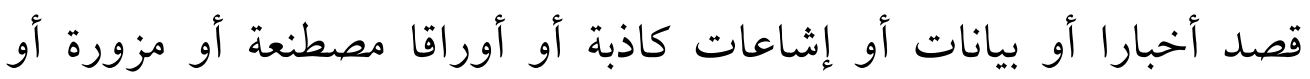

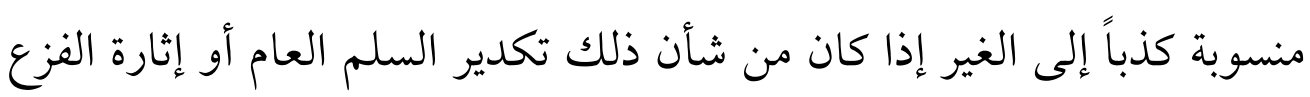
بين الناس أو إلحاق الضرر بالمصلحة العامة. وما نص عليه القانون المصري والشريعة الإسلامية من قبل إنما هو من

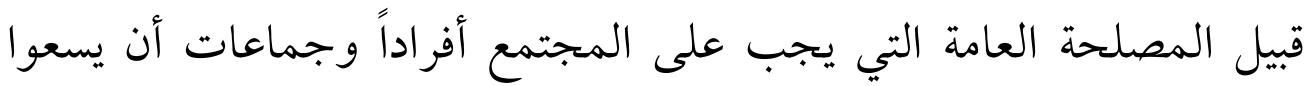
إلى تحصيلها. 


\section{الخاتمة}

بعد هذا العرض السريع لخطر الإشاعات على الفرد والمجتمع ومدى عناية الإسلام بحماية البشرية واستقرارها، نوجز أهم النتائج: 1- حافظ الإسلام على المجتمع واستقراره حفاظاً شديداً. r- وضع الشرع عقوبات لمن يخوض في أعراض الناس. r- إن الإسلام هو الذي حافظ على حقوق الآخرين من مال أو دم أو عرض وهو ما لمسناه فعليا وليس كما نسمع عن -بعض- جمعيات حقوق الإنسان الغربية التي تدعي أنها تحافظ على حقوق الإنسان. ع- خطر الإشاعة عظيم فقد تودي بالمجتمع إلى الهاوية بسبب كلمة تقال بقصد أو من غير قصد كما رأيناه في غزوة أحد عند إشاعة مقتل النبي

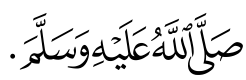

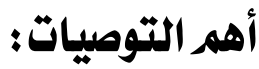

1- على المجتمع أن يتصدى للشائعات وأن يقف بالمرصاد أمام هذه المصيبة التي لا تفرق بين الصالح والطالح.

r- على الدعاة أن يبينوا للناس من خلال الخطب والندوات والمحاضرات خطر هذه الكارثة

r- ولا ننسى أن الإعلام له دور خطير في هذه المهمة فيجب عليه أولا أن لا يروج للشائعات وثانياً أن يتصدى لها.

ع - على الدولة أن تضع ضوابط ومواثيق شرف للإعلاميين، فلا يتحدث الإعلامي إلا عن حقيقة ولا يزين للناس الباطل على أنه حقيقة. 
ه - كذلك النظر في البرامج الحديثة وبالأخص مواقع التواصل الاجتماعي

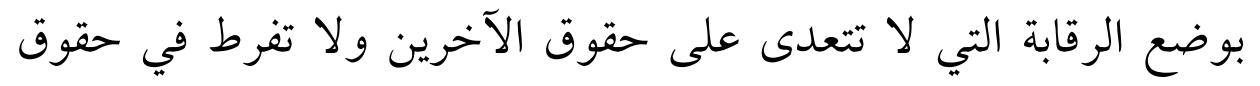

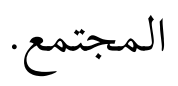

G(2)

العدد السادس والثلاثون .r.r 


\section{فهربس الموضوعات}

الصفحة

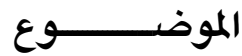

r المقدمة .

$r \varepsilon \wedge$ خطة البحث.

$r \varepsilon q$ تعريف الإشاعة في اللغة ...

$r \varepsilon q$ تعريف الإشاعة في الاصطلاح

ro. أنواع الإشاعات.

rol نماذج من الإشاعات .

r. المبحث الثاني

r. حد القذف في اللغة...

ry. حد القذف في الاصطلاح.

r. الأدلة على تحريم القذف.

rur شروط القاذف

r r شروط المقذوف.

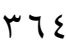
شروط الصيغة

المبحث الثالث: منهج الإسلام في التعامل مع الشائعات ............................. rาy. التثبت من صحة الكلام مان.

rTV الرجوع إلى أهل العلم ruA أن يستعمل الإنسان عقله للوصول إلى الحقيقة

r وضع الشرع عقوبة أخروية لمن لا يتثبت .

rV. الإشاعات في نظر القانون.

rvy الخاتمة.

rV فهرس الموضوعات. 